\title{
1,3-Dipolarna cikloadicija (I. dio): Dobivanje 1,2,3-triazolnih derivata u nukleozidnoj kemiji
}

DOI: $10.15255 / K U I .2014 .020$

KUI-29/2015

Pregledni rad

Prispjelo 8. srpnja 2014. Prihvaćeno 2. rujna 2014.

\author{
D. Saftić, ${ }^{a^{*}}$ L. Krstulović, ${ }^{b}$ M. Bajićb i B. Žinića \\ a Zavod za organsku kemiju i biokemiju, Institut Ruđer Bošković, \\ Bijenička cesta 54, 10000 Zagreb, Hrvatska \\ b Zavod za kemiju i biokemiju, Veterinarski fakultet, Sveučilište u \\ Zagrebu Heinzelova 55, 10000 Zagreb, Hrvatska
}

\begin{abstract}
\| Sažetak
Bakrom katalizirana Huisgenova 1,3-dipolarna cikloadicija azida i terminalnih alkina kojom regioselektivno nastaju 1,4-disupstituirani 1,2,3-triazoli često je primjenjivana metoda sintetske organske kemije. Zahvaljujući jednostavnim reakcijskim uvjetima, zauzela je značajno mjesto i u području nukleozidne kemije jer omogućuje dobivanje velikog broja potencijalno biološki aktivnih spojeva s nizom zanimljivih dodatnih svojstava induciranih uvođenjem 1,2,3-triazolnog strukturnog motiva u molekulu.
\end{abstract}

\| Ključne riječi

Klik-kemija, nukleozidi, 1,2,3-triazolni nukleozidni analozi

\section{Uvod}

Kada je 1953. godine obznanjen model DNA s dvostrukom uzvojnicom te objašnjen princip genetskog koda i uloga nukleinskih kiselina u stanicama, ispitivanje biološke aktivnosti nukleozida i njihovih fosforiliranih derivata postalo je fundamentalno i neiscrpno područje znanstvenog interesa. Prvi radovi iz ovog područja bili su usredotočeni na transformaciju nukleobaze vezane na neki šećer ili je transformacija provedena samo na šećernoj komponenti prirodnog nukleozida. Tek 1974. godine otkrićem prvog primjenjivog antivirusnog lijeka aciklovira ${ }^{1}$ interes se proširio i na spojeve u kojima se nukleobaza i šećerna komponenta značajno razlikuju od prirodnih struktura te je otkriveno da neki od njih imaju antitumorsku, antivirusnu i/ili antibakterijsku aktivnost.

U potrazi za novim biološki aktivnim nukleozidnim derivatima razvijene su brojne metode njihove sinteze. Tako je posljednjih godina intenzivno razvijeno područje primjene paladijem kataliziranih reakcija adicija i supstitucija (Richard F. Heck, Ei-ichi Negishi i Akira Suzuki; Nobelova nagrada za kemiju 2010. godine). Još šezdesetih godina prošlog stoljeća otkrivena je Heckova reakcija ${ }^{2,3,4}$ stvaranja veze ugljik-ugljik, ali je njezina primjena intenzivirana tek osamdesetih godina kada su Bergstrom i sur. objavili nekoliko radova u kojima opisuju reakcije povezivanja nukleozida s alilnim halogenidima, ${ }^{5}$ olefinskim spojevima, ${ }^{6}$ alkoholima i acetatima. ${ }^{7}$ Druga metoda $\operatorname{Pd}(0)$-katalizirane reakcije alkiliranja, tzv. Tsuji-Trostova reakcija, također je

\footnotetext{
* Autor za dopisivanje: Dr. sc. Dijana Saftić e-pošta: dsaftic@irb.hr
}

pokazala velik potencijal zbog široke primjene i relativno jednostavnih reakcijskih uvjeta. ${ }^{3}$

Paladijem katalizirane reakcije mogu se provoditi i s različitim organometalnim spojevima kao što su organokositrovi (Stille), ${ }^{3,8}$ organocinkovi (Negishi), ${ }^{9}$ organosilicijevi (Hiya$\mathrm{ma})^{10}$ ili organoborovi spojevi (Suzuki). ${ }^{3}$

Osnovni razlog za veliku upotrebu paladija u sintezi je to što se stvaranjem nove veze ugljik-ugljik pruža mogućnost novih strukturnih transformacija molekule. $U$ tablici 1 prikazane su najčešće paladijem katalizirane reakcije povezivanja primijenjene u kemiji nukleozida.

Osim što su primjenom paladijem kataliziranih reakcija pripravljeni mnogi biološki aktivni derivati nukleobaza/ nukleozida, takvi spojevi mogu biti i prekursori drugih interesantnih derivata u brojnim reakcijama. $U$ ovom radu bit će prikazane primjene različitih alkinilnih derivata nukleobaza/nukleozida (pripravljenih paladijem kataliziranim reakcijama) u 1,3-dipolarnoj cikloadicijskoj reakciji s azidima u reakcijskim uvjetima koji omogućuju dobivanje 1,2,3-triazolnih specija.

\section{Klik-kemija}

Pojam klik-kemije prvi su put upotrijebili Sharpless i sur. 2001. godine, ${ }^{11}$ a nedvojbeno predstavlja jedan od najpopularnijih pristupa u suvremenoj organskoj sintezi. ${ }^{12} \mathrm{Nji-}$ me su objedinili široku paletu kemijskih reakcija nastajanja veze ugljik-heteroatom u kojima se brzo i pouzdano dolazi do produkata spajanjem više manjih jedinica. Postoji ne- 
Tablica 1 - Pregled najvažnijih Pd-kataliziranih reakcija povezivanja u nukleozidnoj kemiji

Table 1 - Overview of the most important Pd-catalyzed cross-coupling reactions in nucleoside chemistry

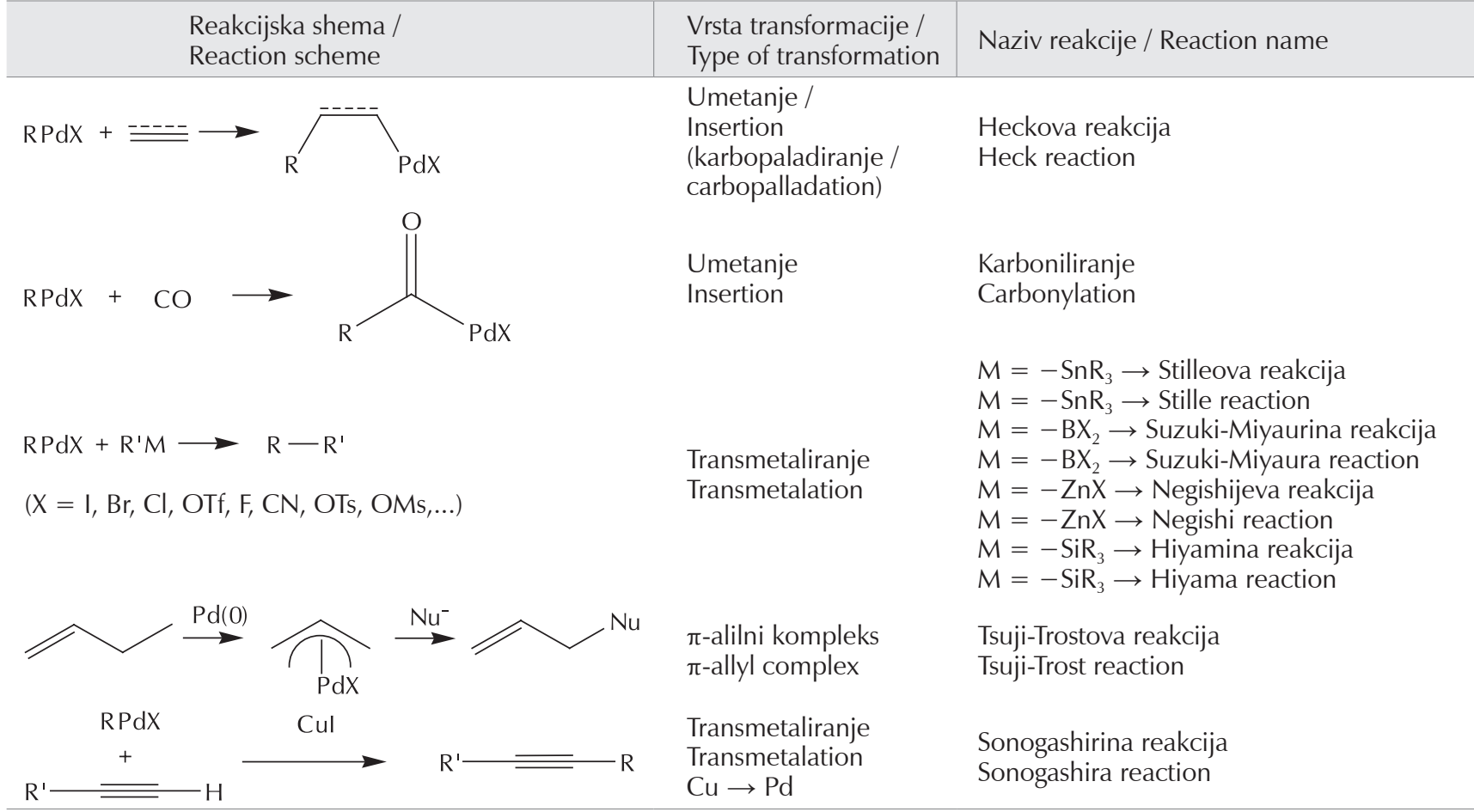

koliko tipova reakcija koje možemo smatrati reakcijama "klik-tipa" (shema 1). ${ }^{11}$

Najzastupljenija od svih reakcija "klik-tipa" upravo je Huisgenova 1,3-dipolarna cikloadicija azida i terminalnog alkina, pri čemu nastaje 1,2,3-triazol. Jedna od prvih sin- teza koja je uključivala reakciju terminalnog ili internog alkina i azida poznata je više od stotinu godina. Naime, prvi 1,2,3-triazol sintetiziran je 1893. godine iz fenil-azida $i$ acetilendikarboksilata. ${ }^{13}$ Rolf Huisgen $i$ sur. detaljno su istražili reakcije 1,3-dipolarne cikloadicije pedesetih godina prošlog stoljeća ${ }^{14}$ te zaključili da je, u termodina-<smiles>[R]OC1=CCC([R])CC1</smiles>

$\mathrm{R}^{2}=$ alkil-, aril-, heteroaril$\mathrm{R}^{2}=$ alkyl-, aryl-, heteroaryl-

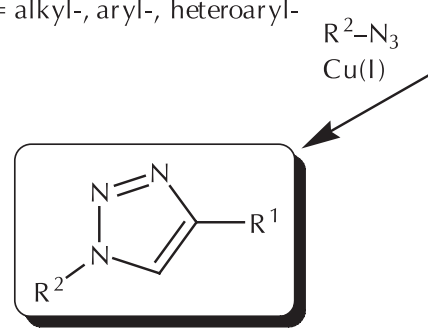

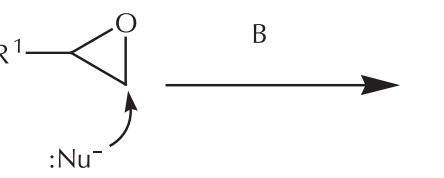<smiles>[R]C(O)C[NH]</smiles>

[O]

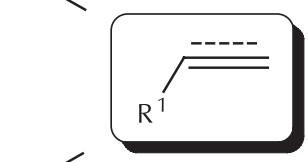

katalizator catalyst

D

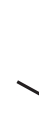

$\mathrm{R}^{1}=$ alkil-, aril-, heteroaril$\mathrm{R}^{1}=$ alkyl-, aryl-, heteroaryl-

C

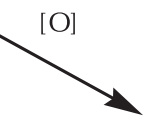<smiles>[R]C(C)=O</smiles>

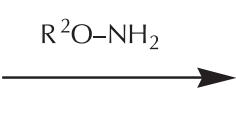<smiles>[R20]N=C([R])C</smiles>

$\mathrm{R}^{2}=$ alkil-, aril-, heteroaril-

$\mathrm{R}^{2}=$ alkyl-, aryl-, heteroaryl-

$\mathrm{R}^{2}=$ alkil-, aril-, heteroaril-

$\mathrm{R}^{2}=$ alkyl-, aryl-, heteroaryl-

Shema 1 - Primjeri reakcija koje udovoljavaju kriterijima klik-reakcija: A) adicije na nezasićenu vezu ugljik-ugljik; B) reakcije nukleofilnog otvaranja prstena; C) karbonilna kemija nealdolnog tipa; D) cikloadicijske reakcije.

Scheme 1 - Examples of reactions which comply with the criteria of click reactions: A) additions to carbon-carbon multiple bond; B) nucleophilic ring opening reactions; C) non-aldol carbonyl chemistry; D) cycloaddition reactions. 
mičkom smislu, ovaj postupak egzoterman $\left(\Delta H^{\circ}=-45\right.$ do $\left.-55 \mathrm{kcal} \mathrm{mol}^{-1}\right)$, ali s relativno visokom energijom aktivacije $\left(E_{\mathrm{a}}=26 \mathrm{kcal} \mathrm{mol}^{-1}\right.$ za reakciju metil-azida i propina). ${ }^{15}$ To značajno utječe na brzinu reakcije, te je ona za neaktivirane reaktante na sobnoj temperaturi vrlo spora. Alkin i azid vrlo su selektivni u reaktivnosti: inertni su prema većini funkcionalnih skupina i stabilni u velikom broju otapala, pri različitim temperaturama i vrijednostima $\mathrm{pH}$. Nekatalizirana reakcija zahtijeva visoku temperaturu i pri tom nastaje smjesa dvaju regioizomera; 1,4-disupstituirani 1,2,3-triazol A i 1,5-disupstituirani 1,2,3-triazol B (shema 2). ${ }^{16}$

\section{Cu(I)-katalizirana azid-alkinska 1,3-dipolarna cikloadicija (CuAAC)}

U posljednjih desetak godina Huisgenova 1,3-dipolarna cikloadicija dolazi u žarište interesa sintetske organske kemije od kada su Tornøe i Meldal 2002. godine upotrijebili bakar(I) kao katalizator. Ova reakcija je od tada poznata kao $\mathrm{Cu}(\mathrm{I})$-katalizirana azid-alkinska cikloadicija (krat. CuAAC, engl. Copper Catalyzed Azide-Alkyne Cycloaddition). ${ }^{16,17} \mathrm{Cu}(\mathrm{I})$-katalizirana 1,3-cikloadicija je do $10^{7}$ puta brža od nekatalizirane reakcije, ${ }^{18}$ odvija se pri temperaturi $0-25{ }^{\circ} \mathrm{C}$, a sterička i elektronska svojstva supstituenata ne utječu bitno na tijek katalizirane reakcije. Reakcijom regioselektivno nastaju 1,4-disupstituirani 1,2,3-triazoli (shema 2) koji su stabilni u hidrolitičkim i oksidoredukcijskim uvjetima te pri visokim temperaturama.

\section{Izvori bakra u CuAAC reakcijama}

Bakar(I) se u reakciju uvodi izravno ili se može pripremiti in situ. Ovisno o reakcijskim uvjetima izabire se i odgovarajući bakrov katalizator. U slučaju polarnih supstrata najčešće se primjenjuje vodeni medij te $\mathrm{CuSO}_{4}$ uz odgovarajuće redukcijsko sredstvo (npr. natrijev askorbat) koje će in situ generirati potrebni $\mathrm{Cu}(\mathrm{I})$. Neposredna primjena katalizatora $\mathrm{Cu}(\mathrm{I})$ najčešće uključuje primjenu soli $\mathrm{Cu}(\mathrm{I})$ (Cul ili $\mathrm{CuBr})$ ili kompleksa $\mathrm{Cu}(\mathrm{I})\left(\left[\mathrm{Cu}\left(\mathrm{CH}_{3} \mathrm{CN}\right)_{4}\right] \mathrm{PF}_{6 \prime}(\mathrm{EtO})_{3} \mathrm{P} \cdot \mathrm{Cul}\right.$,
$\left.\left[\mathrm{Cu}\left(\mathrm{PPh}_{3}\right)_{3}\right] \mathrm{Br}\right)$. Kompleksi su se pokazali kao dobro rješenje kod reakcija u organskim otapalima gdje je topljivost $\mathrm{Cu}(\mathrm{I})$ soli ograničena. Osim Cu(I) i Cu(II) kao izvora bakra poznate su i primjene katalizatora $\mathrm{Cu}(0)$ (bakrena žica ili bakreni prah) ${ }^{19}$ te nanočestica bakra. ${ }^{20} \mathrm{Cu}(\mathrm{I})$ je termodinamički nestabilan te se relativno lako oksidira u $\mathrm{Cu}(\mathrm{II})$ koji je katalitički inaktivan. Cu(II) kao oksidacijsko sredstvo može uzrokovati nastanak neželjenih nusprodukata, a da bi se to spriječilo, reakcije sa solima $\mathrm{Cu}(\mathrm{I})$ treba voditi bez prisutnosti kisika. Kao alternativno rješenje strogo suhim reakcijskim uvjetima u reakcijama CuAAC mogu se upotrijebiti i kompleksi Cu(I) s različitim ligandima. Ligandi štite $\mathrm{Cu}(\mathrm{I})$ od oksidacije, pa nije nužno voditi reakciju bez prisustva kisika, a mogu i poboljšati katalitička svojstva soli $\mathrm{Cu}(\mathrm{I})$. Osim toga, ligandi mogu djelovati i kao akceptori protona, pa nije potrebna upotreba baza. Najčešće upotrebljavan ligand u organskoj sintezi i biokonjugaciji molekula je TBTA (tris[(1-benzil-1H-1,2,3-triazol-4-il)metil] amin), a batofenantrolin i PMEDTA ( $N^{1}$-(2-(dimetilamino) etil)- $N^{1}, N^{2}, N^{2}$-trimetiletan-1,2-diamin) se upotrebljavaju $u$ kemiji polimera. ${ }^{21 a}$

U reakcijama CuAAC upotrebljava se niz nepolarnih te polarnih aprotičnih i protičnih otapala (toluen, 1,4-dioksan, $\mathrm{CHCl}_{3}, \mathrm{CH}_{2} \mathrm{Cl}_{2}$, THF, DMF, $\mathrm{CH}_{3} \mathrm{CN}$, DMSO, NMP, tBuOH, $\mathrm{EtOH}, \mathrm{MeOH}$ ), a moguća je i upotreba vode u smjesi s nekim organskim otapalom (najčešće s EtOH ili $t \mathrm{BuOH}){ }^{21 a}$ Kao baze se najčešće upotrebljavaju diizopropiletilamin (DIPEA), N, N'-dimetiletilendiamin (DMEDA) i $\mathrm{Et}_{3} \mathrm{~N}$, a nešto rjeđe 1,8-diazabiciklo[5.4.0]undek-7-en (DBU), piperidin i 2,6-lutidin. ${ }^{21 a}$

Opći uvjeti za reakciju CuAAC u nukleozidnoj kemiji podrazumijevaju temperaturu $0-25{ }^{\circ} \mathrm{C}$ te $10 \mathrm{~mol} \%$ bakrovog katalizatora, $5 \mathrm{~mol} \%$ redukcijskog sredstva (npr. natrijeva askorbata) i 15 mol \% baze, sve u odnosu na mjerodavni reaktant koji može biti alkin odnosno azid. Postupak obrade reakcije i izolacija produkta uglavnom su vrlo jednostavni te podrazumijevaju filtraciju i prekristalizaciju. S obzirom na to da se radi o potencijalno biološki aktivnim spojevima koji se pripremaju u svrhu bioloških testiranja, posebnu pažnju treba obratiti na kontaminaciju spojeva
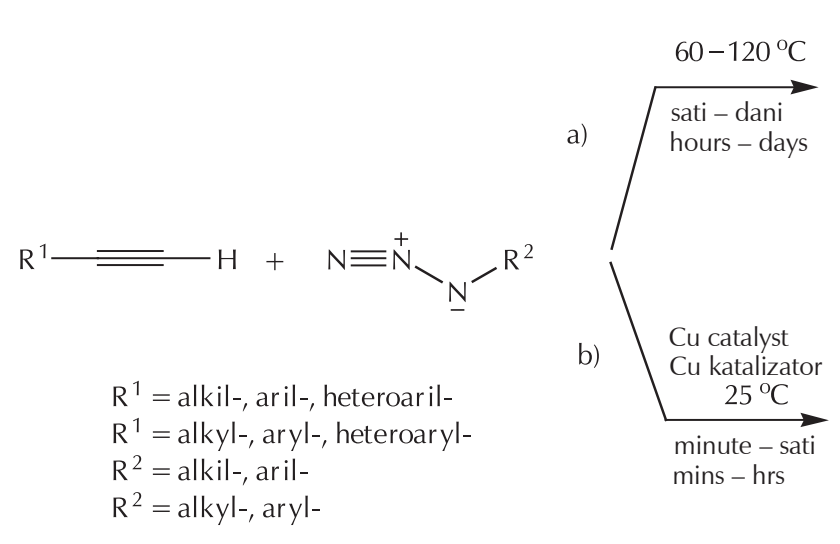<smiles>[R1]c1cn([R])nn1</smiles>

A

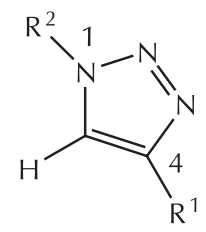

A

Shema 2 - 1,3-Dipolarna azid-alkinska cikloadicija: a) nekatalizirana i b) Cu(I)-katalizirana Scheme 2 - 1,3-Dipolar azide-alkyne cycloaddition: a) uncatalysed, and b) $\mathrm{Cu}(\mathrm{I})$ catalyzed 
bakrovim solima. To je iznimno važan stupanj izolacije, a najuspješniji postupci uklanjanja bakra su filtracija kroz stupac Cellita ili kroz kratki stupac $\mathrm{SiO}_{2} / \mathrm{Al}_{2} \mathrm{O}_{3}$ odnosno tretiranje reakcijske smjese aktivnim ugljenom. ${ }^{21 \mathrm{~b}}$

\section{Mehanizam reakcije CuAAC}

$\mathrm{Na}$ shemi 3 prikazan je pretpostavljeni mehanizam $\mathrm{Cu}$ (I)-katalizirane azid-alkinske 1,3-dipolarne cikloadicije. ${ }^{21 a}$ Oznaka [CuL] podrazumijeva bilo koji bakrov katalizator koji može sudjelovati u reakciji. U Cu(I)-kataliziranim klik-reakcijama sudjeluje isključivo terminalni alkin te u prvom koraku reakcije $\mathrm{Cu}^{+}$koordinira $\pi$-elektrone alkina $\mathrm{i}$ nastaje $\pi$-kompleks bakra i alkina (A). Koordinacijom $\mathrm{Cu}^{+}$ na trostruku vezu ugljik-ugljik smanjuje se $\mathrm{p} K_{\mathrm{a}}$ terminalnog protona alkina, što omogućuje deprotonaciju i nastanak bakrovog acetilida (B). Kompleks bakrovog acetilida koordinira azid, pri čemu nastaje intermedijar $(\mathbf{C})$, a njegovom pregradnjom nastaje šesteročlani prsten (D), u koji je uključen i bakar (Cu-prsten). Taj korak ima računski dobivenu energijsku barijeru 18,7 $\mathrm{kcal} \mathrm{mol}^{-1}$, što je znatno manje od 23,7 $\mathrm{kcal} \mathrm{mol}^{-1}$, koliko iznosi teorijska barijera nekatalizirane reakcije. Energijska barijera za nastajanje triazolila (E) (triazola supstituiranog bakrom) je niska; 3,2 kcal mol-1. Protoniranjem triazolila $\mathbf{E}$ oslobađa se bakar i nastaje produkt 1,4-supstituirani 1,2,3-triazol.
Zbog činjenice da se radi o reakciji drugog reda s obzirom na $\mathrm{Cu}(\mathrm{I})^{22}$ te da acetilidi najčešće koordiniraju barem dva bakrova atoma, pretpostavlja se da azid $\mathrm{i}$ alkin nisu koordinirani istim bakrovim atomom i da u reakciji sudjeluju barem dva bakrova atoma. Proračun DFT (engl. Density Functional Theory) pokazuje da se uz dva bakrova atoma energijska barijera cikloadicije smanjuje za $4 \mathrm{kcal} \mathrm{mol}^{-1}$ (17 kcal mol${ }^{-1}$ u slučaju jednog bakrovog atoma i $13 \mathrm{kcal} \mathrm{mol}^{-1}$ u slučaju dva bakrova atoma). ${ }^{23}$

\section{Reakcije CuAAC u nukleozidnoj kemiji}

Strukturna raznolikost biološki aktivnih nukleozidnih derivata sintetiziranih u posljednjih 50-ak godina evidentno pokazuje da nukleozidni analozi ne moraju nužno biti u uskoj strukturnoj povezanosti s prirodnim nukleozidima, a da bi istodobno bili biološki zanimljivi. Stoga se čini logičnim kako su od otkrića reakcije CuAAC njezine brojne prednosti primijenjene i u ovom neiscrpnom području kemije u sintezi potencijalnih biološki aktivnih nukleozidnih derivata.

U prethodnom poglavlju spomenute su samo neke najčešće primjenjivane metode sinteze terminalnih alkina supstitucijom nukleobaza/nukleozida u paladijem kataliziranim reakcijama. S druge strane, azidnu funkcijsku sku-<smiles>[R]c1cn([R])nn1</smiles>

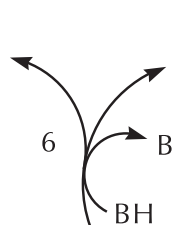<smiles>CCCCC[GeH3]</smiles><smiles>[R]c1nnn([R])c1C(C)(C)C</smiles><smiles>[R]C#CC[C@H](C)C(C)C</smiles><smiles>[R]C#C[AlH2][SiH2][SiH3]</smiles>

A

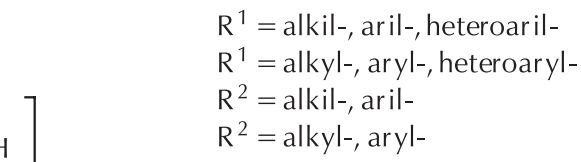

$\mathrm{R}^{1}=$ alkil-, aril-, heteroaril$\mathrm{R}^{2}=$ alkil-, aril$\mathrm{R}^{2}=$ alkyl-, aryl-

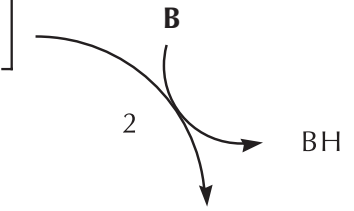<smiles>[R]N=[N+]([Y])[N+]#[N+][R]</smiles>

4 D

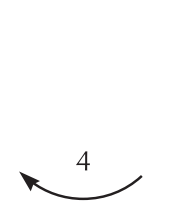<smiles>[R]C#C[Si]([R])([AlH2])[N+]#N</smiles>

C

Shema 3 - Pretpostavljeni mehanizam Cu(I)-katalizirane azid-alkinske 1,3-dipolarne cikloadicije ${ }^{21 a}$ Scheme 3 - Proposed mechanism of the $\mathrm{Cu}(\mathrm{I})$ catalyzed azide-alkyne 1,3-dipolar cycloaddition ${ }^{21 a}$ 
pinu također je moguće generirati na više načina, ${ }^{24}$ a metoda priprave azida često ovisi o tome radi li se o alkil- ili aril-azidu. Najčešći polazni spoj za pripravu azida je neki primarni, sekundarni ili tercijarni halogenid. ${ }^{25}$ Opsežan pregledni rad o pripravi azidonukleozida s karakterističnim reakcijama i biološkim svojstvima objavio je Pathak 2002. godine, ${ }^{26}$ a Andersen i sur. ${ }^{27}$ objavili su iskustva istraživanja utjecaja različitih liganada i otapala u sintezi aril-azida UIImannovom metodom uz $\mathrm{Cu}(\mathrm{I})$ katalizator.

Zbog izrazite opasnosti pri rukovanju organskim azidima male molekulske mase ${ }^{24}$ razvijene su metode sinteze 1,2,3-triazola reakcijom terminalnih alkina i organskih azida pripravljenih in situ (engl. one-pot reakcije). ${ }^{28,29,30}$ Tako su Andersen i sur. ${ }^{31}$ potaknuti metodom koju su razvili Fokin i sur. ${ }^{29}$ objavili učinkovitu metodu sinteze 1-aril-1,2,3-triazola iz aril-halogenida i terminalnih alkina uz prisutnost $\mathrm{NaN}_{3}$. Kumar i sur. ${ }^{32}$ objavili su trokomponentnu metodu priprave 1,2,3-triazolnih derivata klik-reakcijom aromatskih, heterocikličkih i alifatskih terminalnih alkina s azidima pripravljenim in situ iz odgovarajućih $\alpha$-tosiloksiketona.

Kao reagensi trokomponentnih reakcija in situ generiranja azida supstitucijom $\mathrm{s} \mathrm{NaN}_{3}$ osim alkil- ili aril-halogenida i tosilnih derivata mogu se upotrijebiti epoksidi ${ }^{33}$ i Baylis-HiIlmanovi adukti. ${ }^{34}$ Najčešće upotrebljavani reagensi za diazo-transfer na dušik amina su trifluorometansulfonilni azid (triflatni azid, $\mathrm{TfN}_{3}$ ) i trimetilsililni azid $\left(\mathrm{TMSN}_{3}\right)$. ${ }^{35,36} \mathrm{Tim}$ reakcijama mogu se sintetizirati $\alpha$-azidokiseline te alkilni i arilni azidi. Zbog eksplozivne prirode i nestabilnosti $\operatorname{TfN}_{3} \mathrm{U}$ sintezi se kao reagens za transfer azida često upotrebljava imidazol-1-sulfonil-azid hidroklorid. ${ }^{37}$

\section{Modifikacije nukleozida u domeni nukleobaze}

S obzirom na izvanrednu stabilnost triazolnog prstena $u$ kiselim, bazičnim i oksidativnim odnosno reduktivnim uvjetima kao i činjenica da aromatski karakter ovog heterocikličkog sustava omogućuje stvaranje dipol-dipolnih i $\pi$-interakcija, a dušikovi atomi stvaranje vodikovih veza, ovaj strukturni motiv postao je inspiracija za sintezu brojnih klinički primjenjivih nukleozidnih analoga. Poseban doprinos razvoju novih potencijalno biološki aktivnih derivata s ugrađenom strukturom peteročlanog heterocikličkog motiva dala su otkrića danas dobro poznatog ribavirina, koji ima primjenu u terapiji hepatitisa C (krat. HCV, engl. Hepatitis $\boldsymbol{C}$ Virus) ${ }^{38}$ i mizoribina ${ }^{39}$ kao imunosupresivnog agensa te niza sličnih struktura.

U dizajnu novih struktura do izražaja je došla primjena 1,3-dipolarne cikloadicije koja je rezultirala sintezom niza nukleozidnih analoga. ${ }^{40}$ Primjenom klik-kemije Wilkinson $i$ sur. ${ }^{41}$ objavili su sintezu serije $\beta$-arabinoglikozil-triazola $\mathbf{1}$ a-f supstituiranih različitim hidrofobnim lancima kao strukturnih analoga poznatog mikobakterijskog inhibitora biosinteze stanične stijenke; dekaprenolfosfoarabinoze $\mathbf{2}$ (slika 1).

$\mathrm{R}$

a) $-\left(\mathrm{CH}_{2}\right)_{5} \mathrm{CH}_{3}$

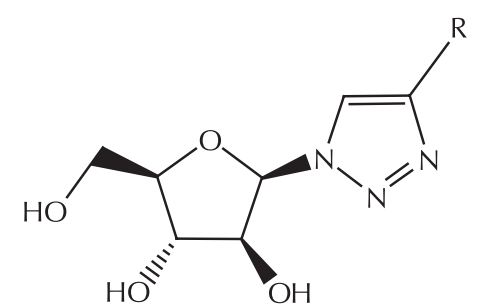

1a-f b) $-\left(\mathrm{CH}_{2}\right)_{7} \mathrm{CH}_{3}$

c) $-\left(\mathrm{CH}_{2}\right)_{9} \mathrm{CH}_{3}$

d) $-\mathrm{CH}_{2} \mathrm{O}\left(\mathrm{CH}_{2}\right)_{13} \mathrm{CH}_{3}$<smiles>CC(C)=CCC/C(C)=C/CC/C(C)=C/COCS</smiles>

f)<smiles>Cc1ccccc1</smiles>

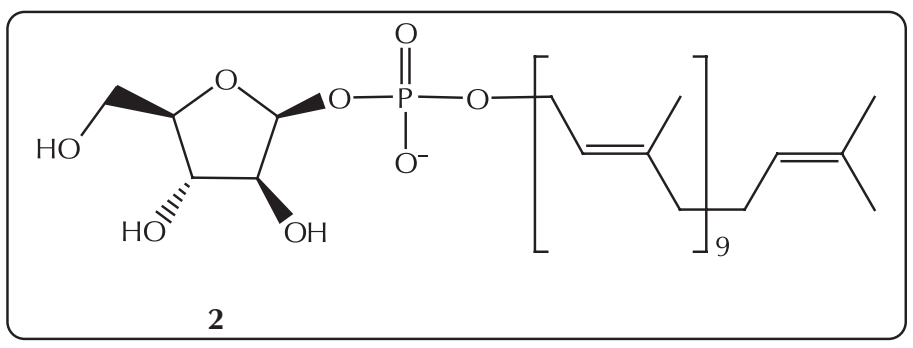

Slika 1 - Strukturni analozi dekaprenolfosfoarabinoze 2

Fig. 1 - Structural analogs of decaprenolphosphoarabinose $\mathbf{2}$ 
Istraživanjima utjecaja strukturnih analoga nukleozida na inhibiciju rasta mikobakterija bavili su se i Singh $i$ sur. ${ }^{42}$ Sintetizirali su seriju $\alpha$-D-ksilo-, $\beta$-D-ribo- i $\alpha$-D-arabinofuranozidnih triazolnih derivata (slika 2) iz odgovarajućih 5'-azidošećera i niza terminalnih alkina te su testirali njihova biološka svojstva na staničnoj liniji Mycobacterium tuberculosis H37Rv.

Kako bi izbjegli primjenu bakra u katalitičkoj reakciji 1,3-dipolarne cikloadicije, Youcef $i$ sur. ${ }^{43}$ istražili su mogućnosti primjene surfaktanata (površinski aktivnih tvari) i tzv. micelarnu katalizu. ${ }^{44}$ Prema prije objavljenim radovima pretpostavili su kako bi ta vrsta katalize mogla ubrzati kemijsku reakciju i kontrolirati regioselektivnost 1,3-dipolarne cikloadicije. Zaključili su da je bakar moguće zamijeniti nekim surfaktantom u reakciji 1,3-dipolarne cikloadicije mono- i disupstituiranih ribozil-alkina s benzil-azidom prilikom sinteze analoga ribavirina. Odabir odgovarajućeg surfaktanta ovisi o tome sudjeluje li u reakciji mono- ili disupstituirani ribozil-alkin.

Zbog sve veće važnosti kemijski promijenjenih oligonukleotida u svrhu povećanja stupnja selektivnog prepoznavanja i mogućnosti primjene ovih lanaca kao biološkog "alata" molekularne biologije i dijagnostike Nakahara $i$ sur. ${ }^{45}$ primijenili su klik-kemiju. U tu svrhu ugradili su 1-etinil-2-deoksi- $\beta$-D-ribofuranozu (6) (shema 4) u oligonukleotidni lanac. Reakcijom CuAAC modificiranog oligonukleotida s različitim primarnim, sekundarnim, tercijarnim i aromatskim azidima dobili su oligonukleotide supstituirane s 1,2,3-triazolnim prstenom (shema 4). Oni u svojoj strukturi sadržavaju C-nukleotidne analoge u kojima je umjesto nukleobaze vezan triazolni prsten na anomernom centru 2-deoksiriboze.<smiles>[R]c1cn(CC2O[C@@H]3OC(C)(C)O[C@@H]3[C@@H]2O)nn1</smiles>

3a-e<smiles>[R]c1cn(CC2O[C@@H](OC)[C@H]3OC(C)(C)O[C@@H]23)nn1</smiles>

4a-e

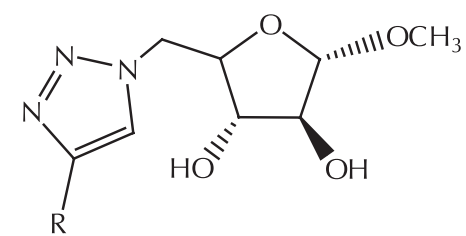

5a-e
a) $\mathrm{R}=$ fenil
a) $\mathrm{R}=$ phenyl
b) $\mathrm{R}=-\mathrm{CH}_{2} \mathrm{OH}$
c) $\mathrm{R}=n$-heksil
b) $\mathrm{R}=-\mathrm{CH}_{2} \mathrm{OH}$
d) $R=n$-pentil
c) $\mathrm{R}=n$-hexyl
e) $R=$ benzil
e) $R=$ benzyl

Slika 2 - $\alpha$-D-ksilo- 3a-e, $\beta$-D-ribo- 4a-e i $\alpha$-D-arabinofuranozidni triazolni derivati 5a-e

Fig. $2-\alpha$-D-xylo- 3a-e, $\beta$-D-ribo- 4a-e, and $\alpha$-D-arabinofuranose triazole derivatives 5 a-e

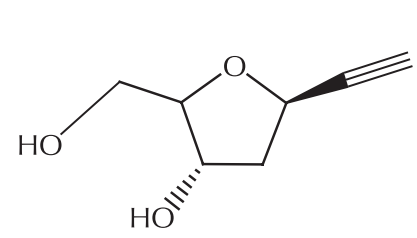

6
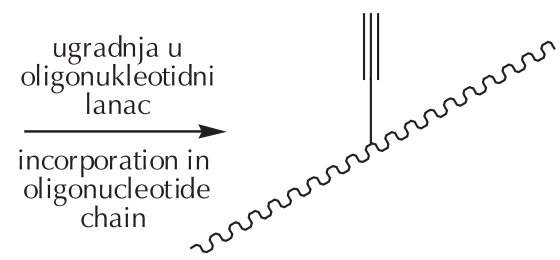
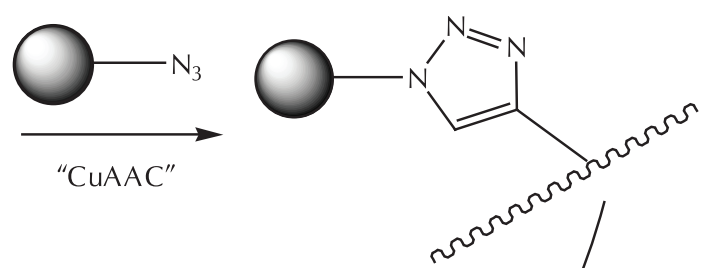

C-nukleotidni analog

C-nucleotide analog<smiles></smiles>

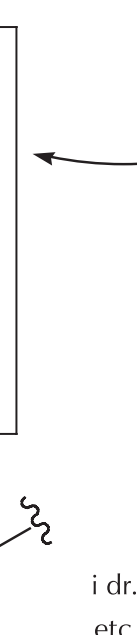<smiles>[C]C1CCCCC1</smiles><smiles>O=[N+]([O-])C12CC3CC(CC(C3)C1)C2</smiles><smiles>[Z]c1ccc(C)cc1</smiles>

Shema 4 - Sinteza oligonukleotidnih lanaca modificiranih 1,2,3-triazolnim nukleotidnim analozima ${ }^{a}$ Scheme 4 - Synthesis of oligonucleotide chains modified with 1,2,3-triazole nucleotide analogs 
Kako bi se poboljšalo iskorištenje i skratilo vrijeme reakcija, sve je češće u primjeni mikrovalno zračenje kao alternativni izvor energije. ${ }^{46}$ Taj nekonvencionalni izvor zračenja našao je svoju primjenu u klik-kemiji. ${ }^{47}$ Sa stajališta tzv. "zelene kemije" značajnu primjenu ima mikrovalnim zračenjem potpomognuta sinteza bez prisutnosti otapala. ${ }^{48}$ Tako su Guezguez i sur. ${ }^{49}$ objavili Cu(I)-kataliziranu regioselektivnu sintezu funkcionaliziranih $\alpha$ - ili $\beta$-1,2,3-triazolil-nukleozinih analoga primjenom reakcije CuAAC između $\alpha$ - ili $\beta$-2-deoksiriboze s različitim terminalnim alkinima. Reakcije su provedene u mikrovalnom reaktoru bez prisutnosti otapala i pri atmosferskom tlaku. Optimiziranjem reakcijskih uvjeta trajanje reakcije je skraćeno s $24 \mathrm{~h}$ na samo 1,5-3 min.

Li i sur. ${ }^{50}$ također su proveli modifikaciju nukleozida u domeni nukleobaze u potrazi za novim analozima cADPR. Poznato je da ciklička adenozin-difosfat-riboza (krat. cAD-
PR, engl. Cyclic ADP Ribose) kontrolira $\mathrm{Cu}^{2+}$-ovisni stanični odgovor brojnih sustava, a strukturni derivati te molekule mogli bi pomoći u objašnjavanju mehanizma posredovanja CADPR-a u $\mathrm{Cu}^{2+}$-ovisnoj staničnoj signalizaciji. Li i sur. ${ }^{50}$ su sintetizirali 4-amido-1,2,3-triazolne nukleozidne analoge 7a-b (slika 3). Preliminarna farmakološka ispitivanja pokazala su da sintetizirani derivati induciraju otpuštanje iona $\mathrm{Cu}^{2+} \mathrm{u}$ intaktnim humanim stanicama Jurkat.

Xia $i$ sur. ${ }^{51}$ sintetizirali su bistriazolil-nukleozidne analoge kao potencijalne agense za liječenje virusa mozaične bolesti duhana (krat. TMV, engl. Tobacco Mosaic Virus) primjenom reakcije CuAAC, a O'Mahony i sur. ${ }^{52}$ su sintezom adenozinskih dimera povezanih 1,2,3-triazolnim prstenom pokazali da je reakcija CuAAC izvediva i na elektronima siromašnim heterocikličkim sustavima kao što su primjerice purini (slika 4). Oni su u reakciji 8-etiniladenozina s 2'-azidoadenozinom izolirali adenozinski dimer 8 .<smiles></smiles>

CADPR<smiles>[X]CCOP(=O)([O-])OP(=O)([O-])OC[C@H]1O[C@@H](n2cc(C(=O)NCCO)nn2)[C@H](O)[C@H]1O</smiles>

7a-b a) $\mathrm{X}=-\mathrm{CH}_{2-}$

b) $\mathrm{X}=-\mathrm{OCH}_{2}-$

Slika 3 - Struktura cADPR i strukturnih analoga $\mathbf{7 a - b}$

Fig. 3 - Structure of CADPR and its structural analogs $7 \mathbf{a}-\mathbf{b}$<smiles>CC(C)[Si]1(C(C)C)OC[C@H]2O[C@@H](n3c(-c4cn(C5[C@H]6O[Si](C(C)C)(C(C)C)O[Si](C(C)C)(C(C)C)OC[C@H]6O[C@H]5n5cnc6c(N)ncnc65)nn4)nc4c(N)ncnc43)C(O)[C@@H]2O[Si](C(C)C)(C(C)C)O1</smiles>

Slika 4 - Struktura adenozinskog dimera $\mathbf{8}$

Fig. 4 - Structure of adenosine dimer $\mathbf{8}$ 
Posljednjih godina veliku ekspanziju doživjelo je područje fluorescentnih nukleozidnih analoga u okviru studija struktura nukleinskih kiselina i proučavanju bioloških svojstava kao što su replikacija, transkripcija, rekombinacija i mehanizmi popravka. ${ }^{53}$ Najčešći nukleozidni fluorescentni analozi uglavnom su derivati purina. Najviše se upotrebljava 2-aminopurin, a komercijalno su dostupni i derivati pterina i pteridina.
O’Mahony i sur. ${ }^{52,54}$ opisali su funkcionalizaciju C8 položaja adenozina koja je rezultirala sintezom derivata s fluorescentnim svojstvima. Isti sustav upotrijebila je Dyrager sa sur. ${ }^{55}$ te su primjenom reakcije CuAAC u mikrovalnom reaktoru uz prethodnu funkcionalizaciju položaja C8 adenozina pripravili 8-(1H-1,2,3-triazol-4-il) adenozinske analoge 10a-i Sonogashirinom metodom (shema 5).

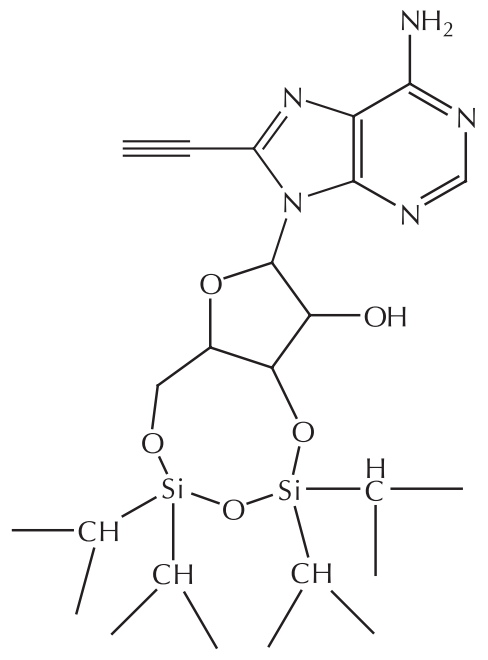

9

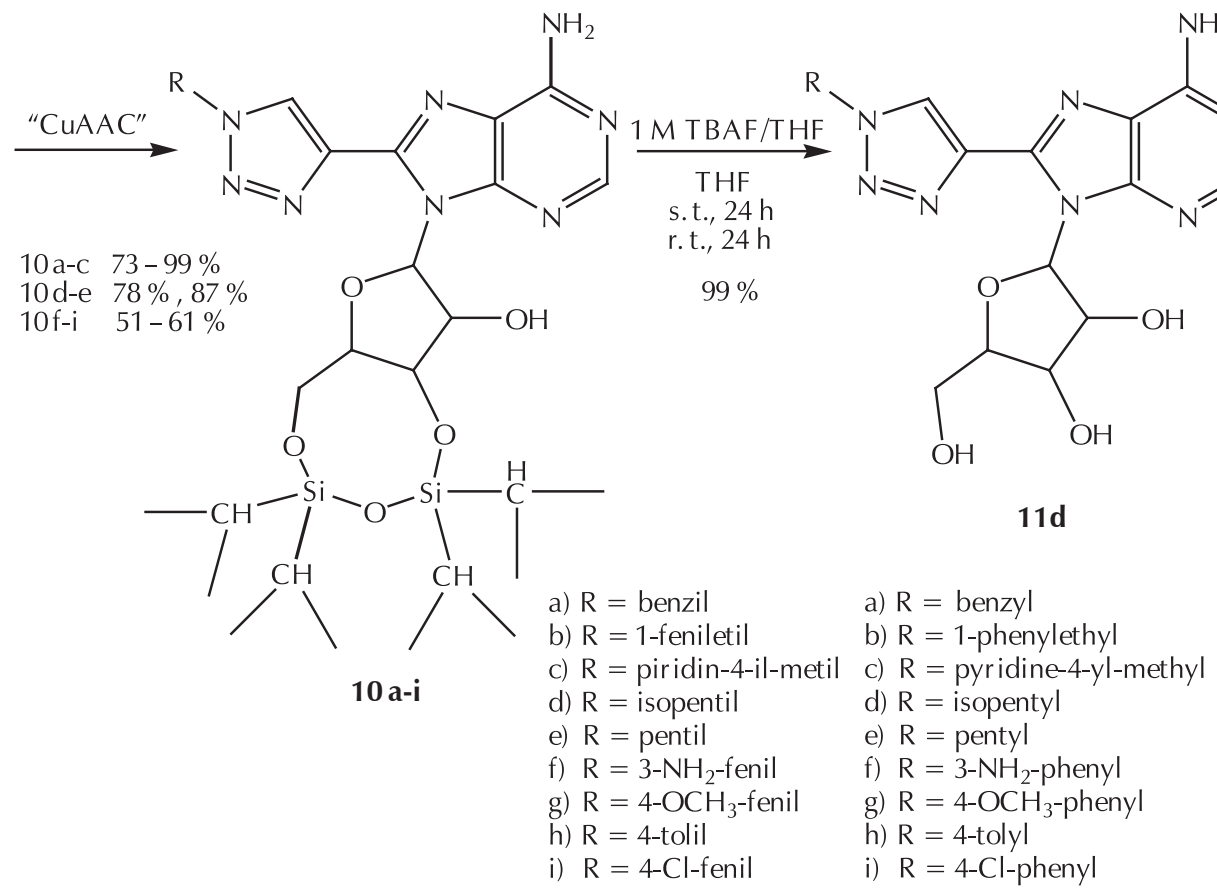

Shema 5

Scheme 5

Pripravljeni spojevi pokazali su veliku sposobnost apsorpcije (ekstinkcijski koeficijenti, $\varepsilon>24000 \mathrm{M}^{-1} \mathrm{~cm}^{-1}$ ), visoku efikasnost emisije apsorbiranog zračenja (kvantni prinos fluorescencije, engl. quantum yield, $\Phi_{\mathrm{F}}>64 \%$ ) te visok faktor osvjetljenja $\left(\varepsilon \cdot \phi_{\mathrm{F}}\right)$ kao i usklađene i usporedive valne duljine emisije u ovisnosti o vrsti supstituenta na triazolnom prstenu.
Prema statistici Svjetske zdravstvene organizacije (krat. WHO, engl. World Health Organization) godišnje umre 7,6 milijuna ljudi od posljedica tumorskog oboljenja. ${ }^{56}$ lako rizik oboljenja raste s godinama, njima su sve više pogođene i mlađe populacije. Pet najčešćih organa koje zahvaća karcinom su pluća, jetra, crijeva, želudac i dojke, a sve učestalija smrtnost posljedica je i raka grlića 
vrata maternice i karcinoma prostate. Među prvim otkrivenim onkološki primjenjivim terapeuticima upravo su nukleozidni analozi (kladribin, klofarabin, kapecitabin, citarabin, fludarabin, gemcitabin, decitabin, floksuridin i dr.). ${ }^{57}$ Meneni i sur. ${ }^{58}$ su 2007. godine objavili sintezu serije 5-etinil-2'-deoksiuridinskih analoga s protutumor- skom aktivnošću, a Lee i sur. ${ }^{59}$ upotrijebili 5-etinil-2'-deoksiuridinski derivat u reakciji CuAAC priprave triazola 14a-d (shema 6).

Sintezom C5-triazolil-2'-deoksiuridinskih derivata te antivirusnim ${ }^{60}$ i protutumorskim ${ }^{61}$ testiranjima pripravljenih spojeva bavili su se i drugi autori.<smiles>O=c1[nH]c(=O)n(C2CC(O)C(CO)O2)cc1I</smiles>

12

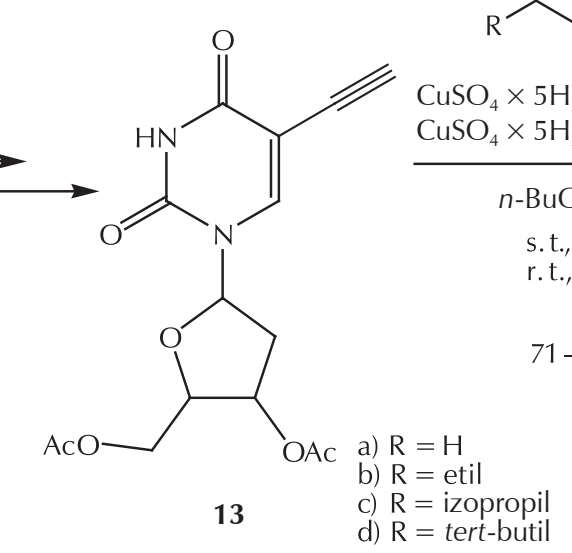<smiles>[R]c1ccc(CN)cc1</smiles><smiles>[R]c1ccc(Cn2cc(-c3cn(C4CC(O)C(CO)O4)c(=O)[nH]c3=O)nn2)cc1</smiles>

a) $\mathrm{R}=\mathrm{H}$

a) $\mathrm{R}=\mathrm{H}$

d) $\mathrm{R}=$ tert-butyl 15a, 15d

Shema 6

Scheme 6 


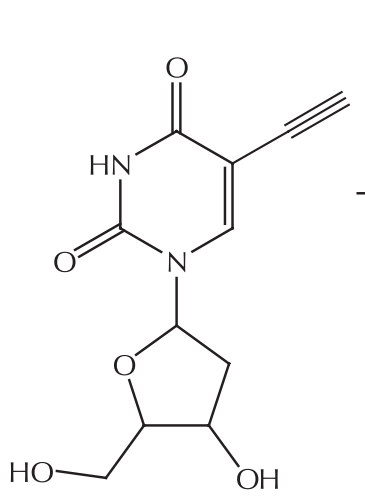

16

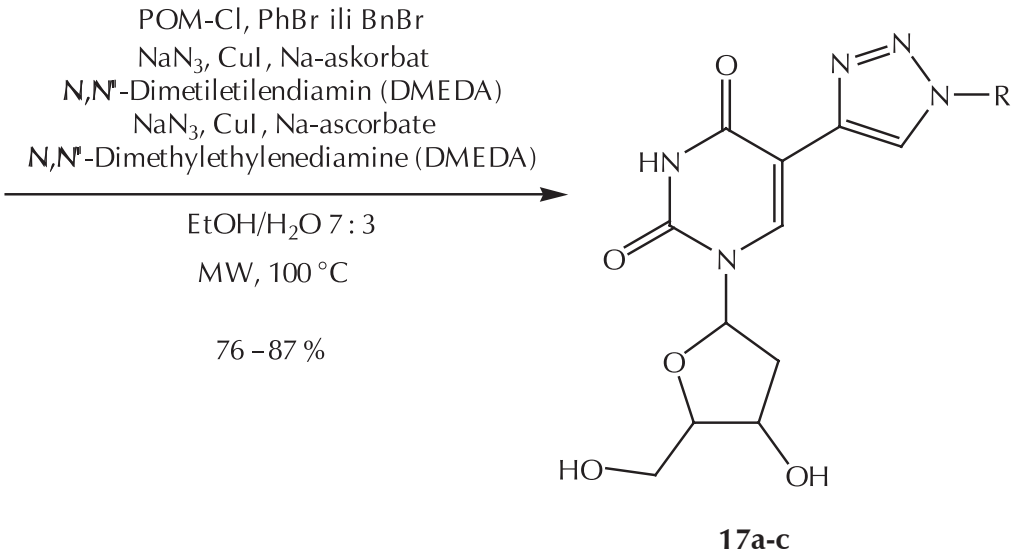

1. DMTr-Cl, piridin, $\mathrm{CH}_{3} \mathrm{CN}$

2. $\mathrm{EtN}(\mathrm{i} \mathrm{Pr})_{2}, \mathrm{CH}_{2} \mathrm{Cl}_{2}$

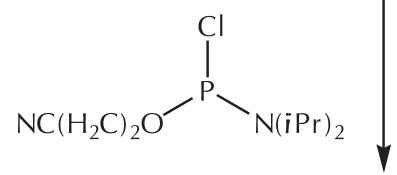

$53-55 \%$
a) $\mathrm{R}=\mathrm{POM}$
b) $R=$ fenil
a) $R=P O M$
c) $\mathrm{R}=$ benzi
b) $R=$ phenyl
c) $R=$ benzy

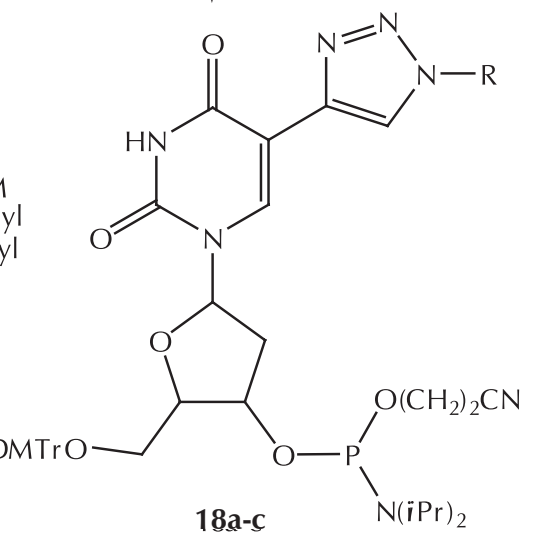

Shema 7

Scheme 7

Osim bioloških testiranja brojni radovi govore i o ugradnji C5-modificiranih pirimidinskih analoga unutar dvostruke uzvojnice RNA/DNA te njihovom utjecaju na stabilnost. Dobiveni rezultati potvrdili su da upravo supstitucija nekim heterocikličkim peteročlanim prstenom povećava stabilnost dvostruke uzvojnice. ${ }^{62}$ Kočalka $i$ sur. ${ }^{62 c}$ su u dvostruku uzvojnicu DNA:RNA ugradili C5-triazolil-2'-deoksiuridinske analoge 18a-c (shema 7).

Iz dobivenih rezultata utjecaja ugrađenih triazolnih struktura u veliki utor dvostruke uzvojnice zaključili su općenito da jedan ugrađeni triazolni derivat unutar oligonukleotidnog lanca destabilizira dvostruku uzvojnicu, dok četiri uzastopno povezana analoga imaju suprotan efekt. Vrsta supstituenta na triazolnom prstenu dodatno može (de)stabilizirati sustav. Andersen $i$ sur. ${ }^{63}$ proveli su stoga sustavnu studiju utjecaja fenilnog i $p$-supstituiranog fenilnog supstituenta na triazolnom prstenu 2'-deoksiuridina na jakost $\pi-\pi$ interakcija unutar lanaca dvostruke uzvojnice. Nakon provedenih hibridizacijskih studija UV spektroskopijom (određivanje $T_{\mathrm{m}}$ ) te studija utjecaja $\pi-\pi$ interakcija u ovisnosti o stupnju (broju ugrađenih modificiranih monomera) i vrsti ugrađenih monomera primjenom cirkularnog dikroizma (krat. CD, engl. Circular Dichroism) autori su zaključili da se modifikacijom oligonukleotidnog lanca stabilnost dvostruke uzvojnice DNA:RNA povećava. Nadalje, najjače $\pi-\pi$ interakcije i stoga najstabilniju dvostruku uzvojnicu omogućile su modifikacije oligonukleotidnog lanca ugradnjom monomera sa sulfonamidnim supstituentom.

\section{Modifikacije nukleozida u domeni šećera i nukleozidni biokonjugati}

Osim strukturnih modifikacija nukleozida u domeni nukleobaze, s ciljem pronalaska novih potencijalno biološki aktivnih derivata, provedene su i strukturne promjene u domeni šećera. I u ovom području značajnu primjenu nalazi reakcija CuAAC u sintezi različitih pirimidinskih ${ }^{64} \mathrm{i}$ purinskih ${ }^{65}$ nukleozidnih analoga.

Osim modifikacija šećernog dijela molekule nukleozida, furanozni prsten moguće je i potpuno zamijeniti nekim heterocikličkim ili čak acikličkim supstituentom. Tako su 


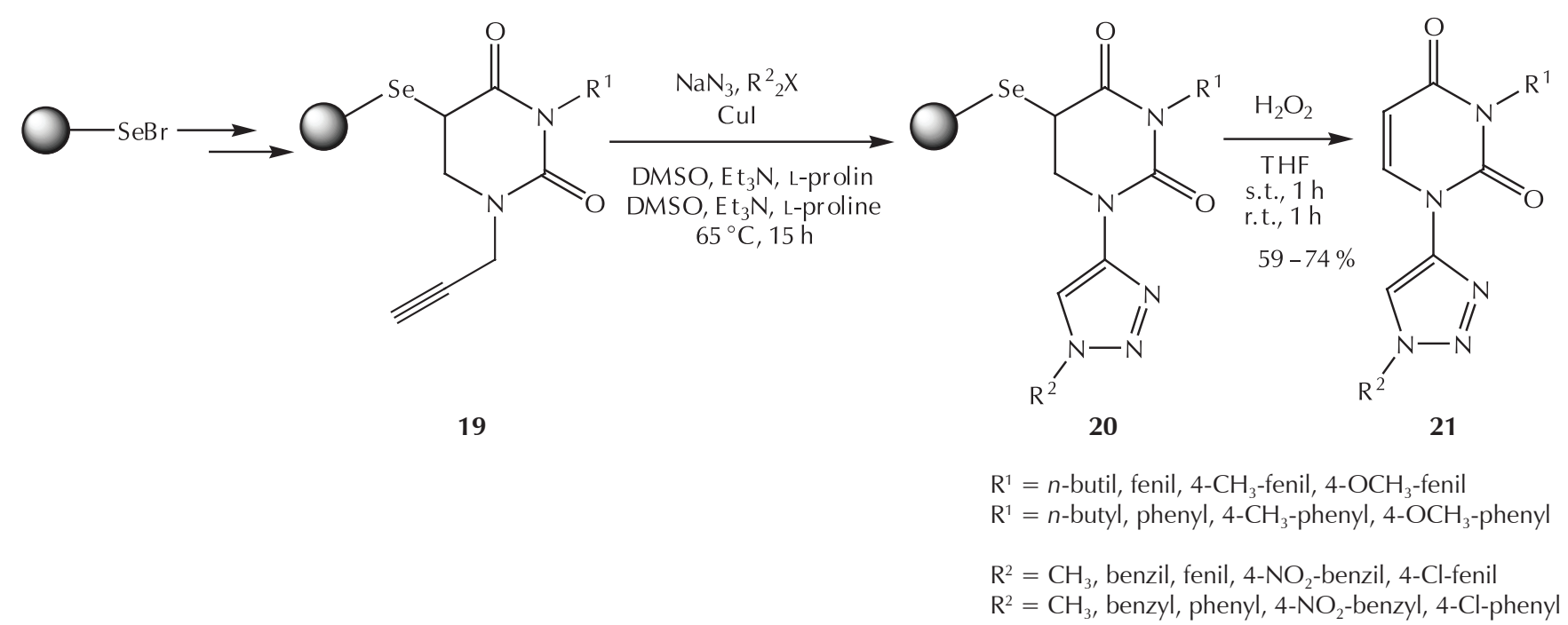

Shema 8

Scheme 8

Cao i Huang ${ }^{66}$ objavili paralelnu sintezu serije uridinskih analoga na čvrstom nosaču selenidne smole primjenom reakcije CuAAC kao ključnog reakcijskog stupnja (shema 8).

Poznati antivirusni agens tenofovir te njegovi strukturni analozi cidofovir i adefovir primjeri su acikličkih nukleozidnih derivata. ${ }^{67}$ Prije 25 godina koncept zamjene šećernog dijela molekule nukleozida acikličkim supstituentom postao je temeljem razvoja derivata s potencijalnim antivirusnim djelovanjem.

$\mathrm{S}$ bogatim ranije stečenim iskustvom priprave modificiranih 1,2,3-triazolilnih aciklonukleozida Elayadi i sur. ${ }^{68}$ objavili su sintezu modificiranih struktura poznatih antivirusnih spojeva primjenom 1,3-dipolarne cikloadicije. Autori su unutar acikličkog supstituenta ugradili triazolni prsten, čime su fleksibilnost strukture dodatno ograničili (slika 5). Osim toga, variranjem duljine lanca pripravljenih acikličkih nukleozidnih triazolil-fosfonata pratili su utjecaj na biološku aktivnost testiranih spojeva na HCV i HIV (engl. $\boldsymbol{H u}$ man Immunodeficiency Virus). Pronašli su da duljina lanca nema dramatičan utjecaj na aktivnosti i citotoksičnost u slučaju pirimidinskih derivata, dok u slučaju purinskih analoga duljina lanca utječe na aktivnost.

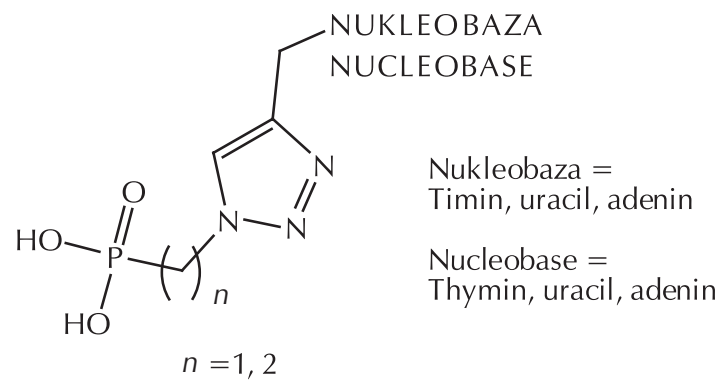

Slika 5 - Strukturni motiv acikličkih nukleozidnih triazolil-fosfonatnih analoga

Fig. 5 - Structure motive of acyclic nucleoside triazolyl-phosphonate analogs
Trakossas i sur. ${ }^{69}$ pripravili su slične triazolom modificirane nukleozide s jednom ili dvjema nukleobazama u svrhu biološke evaluacije antioksidativne aktivnosti. Preliminarna biološka istraživanja pokazala su da neki derivati timina i adenina s triazolom sprječavaju lipidnu peroksidaciju i time mogu imati značajan utjecaj na bolesti starenja, uključujući aterosklerozu, mrenu, reumatoidni artritis i neurodegenerativne poremećaje.

Osim u sintezi nukleozidnih mono-derivata modificiranih u domeni šećera, reakcija CuAAC primjenjivana je i u dizajnu nukleozidnih biokonjugata ${ }^{70}$ i modificiranih oligonukleotida. ${ }^{71,72}$

\section{Primjena triazolnih nukleozidnih derivata}

Od otkrića i adaptacije Huisgenove 1,3-dipolarne [3 + 2] azid-alkinske cikloadicije uvođenjem $\mathrm{Cu}(\mathrm{I})$ katalizatora reakcija CuAAC nije dobila samo naziv "klik" nego je općenito postala sinonimom brze, svestrane i jednostavne sintetske metode sa širokim područjem primjene. Upravo je stoga značajno utjecala na razvoj velikih klastera spojeva $\mathrm{s}$ potencijalnom primjenom u biološkim sustavima. Osim toga, veoma široka primjena CuAAC reakcije očituje se u iznimno velikom broju radova iz različitih područja; dizajn novih lijekova, ${ }^{73}$ biokonjugacija, ${ }^{74}$ kemija polimera i razvoj novih materijala, ${ }^{75}$ supramolekularna kemija, ${ }^{76}$ označavanja DNA ${ }^{77}$ i sinteze oligonukleotida, ${ }^{78}$ povezivanja glikozidnih klastera ${ }^{79}$ i dendrimera, ${ }^{80}$ pripremi stacionarnih faza za kolone ${ }^{81}$ za HPLC i dr.

Kao veliko područje primjene reakcije CuAAC posebno se izdvajaju modifikacije nukleinskih kiselina i njihovih oligomera. Kako je dano u dosadašnjem pregledu literature, nukleinske kiseline moguće je modificirati na tri karakteristična položaja: nukleobazi, šećeru ili fosfodiesterskoj internukleotidnoj vezi. Ipak, najčešća je modifikacija upravo ona na nukleobazi zbog prisutnosti reaktivnih mjesta, relativno kratkih sintetskih putova i široke primjene tako 
derivatiziranih produkata. Prednosti modifikacija nukleobaze u odnosu na šećer ili fosfatnu okosnicu su što takve modifikacije još uvijek ne ometaju produljenje polinukleotidnog lanca, 82 a očuvana je i komplementarnost dvostruke uzvojnice jer nisu narušene Watson-Crickove interakcije. ${ }^{83}$ Pozicije modifikacija nukleobaza su različite i kod purina uglavnom obuhvaćaju položaj N7 (7-aza i 7-deaza-derivati), položaj N9 te supstitucije egzocikličkih amino-skupina adenina i gvanina. Kod pirimidina je najčešća modifikacija na položaju C5 nukleobaze, zatim supstitucija egzocikličke amino-skupine citozina te položaj N1 pirimidina. Ipak, kako bi se izbjegla modifikacija Watson-Crickove regije i omogućila ugradnja modificiranih nukleotida upravo u veliki utor dvostruke uzvojnice DNA/RNA, najčešće se modificiraju položaj C5 kod pirimidinskih te položaji N7 i C8 purinskih nukleobaza.

Triazolni purinski odnosno pirimidinski analozi specifično označeni radikalskim supstituentima našli su primjenu i u proučavanju struktura i konformacija oligomera DNA i RNA elektronskom paramagnetskom rezonancijom/spektroskopijom elektronske spinske rezonancije (krat. EPR/ ESR, engl. Electron Paramagnetic Resonance/Electron Spin Resonance), ${ }^{84}$ a specifično obilježeni derivati, najčešće radioaktivnim fluorom $\left({ }^{18} \mathrm{~F}\right)$, upotrebljavaju se u praćenju distribucije i ponašanja bioaktivnih molekula u uvjetima in vivo pozitronskom emisijskom tomografijom (krat. PET, engl. Positron Emission Tomography). ${ }^{85}$

Doprinos reakcije CuAAC očituje se i u vezanju različitih fluorescentnih markera na nukleobaze, a nerijetko je fluorescencija posljedica samog generiranja triazolnog prstena (npr. položaj C8 adenozina). ${ }^{55,86}$ Prvi primjer fluorescencije inducirane uvođenjem triazolnog prstena u sustav primjenom reakcije CuAAC bez vezanja dodatnog fluorofora bila je sinteza citidinskog analoga 22, ${ }^{87}$ a iste godine sintetiziran je i uridinski analog 23 klik-konjugacijom fluorofora Nile Red (slika 6). ${ }^{88}$

Primjenom klik-kemije Ostergaard i sur. ${ }^{53}$ vezali su pirenski fluorofor na položaj C5 uridina te tako priredili analog 24 (slika 6). On se pokazao iznimno uspješnim u detekciji polimorfizma pojedinačnog nukleotida (krat. SNP, engl. Single-Nucleotide Polymorphism) zbog smanjenja efikasnosti emisije apsorbiranog zračenja $\left(\Phi_{\mathrm{F}}\right)$ u prisutnosti pogrešno sparenih sekvencija (engl. mismatched sequences).

Fluorescentni oligonukleotidni sustavi predstavljaju značajan biološki alat za vizualizaciju specifičnih svojstava nastalih njihovim povezivanjem s ciljanim oligonukleotidima ili proteinima, a također mogu dati i brojne informacije o odnosu strukture i reaktivnosti (krat. SAR, engl. Structure-Activity Relationship).

O prisutnosti 1,2,3-triazolnog prstena kao ključnog farmakofora biološki aktivnih molekula ${ }^{89}$ svjedoči nekoliko potencijalnih farmaceutika u posljednjem stadiju kliničkih ispitivanja, koji u svojoj strukturi sadrže upravo ovaj prsten. ${ }^{90}$ Pored brojnih primjera prisutnosti 1,2,3-triazola kao strukturnog motiva molekula s biološkom aktivnošću, 1,2,3-triazolni heterocikli pronašli su i širu industrijsku primjenu. Tako se danas upotrebljavaju kao boje i fotostabilizatori u industriji optičkih vlakana, ${ }^{91}$ inhibitori korozije metala i legura, ${ }^{92}$ svjetlosni stabilizatori organskih materijala i polimera te $u$ agronomiji kao insekticidi, ${ }^{93}$ fungicidi, ${ }^{94}$ herbicidi i regulatori rasta. ${ }^{95}$<smiles>CCCn1cc(-c2cn(C3CC(OP(=O)(O)OC)C(COS)O3)c(=O)[nH]c2=O)nn1</smiles>

Slika 6 - Primjeri fluorescentnih pirimidinskih derivata

Fig. 6 - Examples of fluorescent pyrimidine derivatives 


\section{Zaključak}

Posljednjih petnaest godina značajno mjesto u sintetskoj kemiji zauzima 1,3-dipolarna cikloadicijska reakcija azida i terminalnih alkina. Razlog tome su ponajprije jednostavni reakcijski uvjeti i iznimno širok spektar primjene različitih supstrata. Upravo zato ova sintetska metoda ima veliku primjenu i u području nukleozidne kemije gdje je transformacijama u domeni nukleobaze odnosno šećerne komponente pripravljen niz biološki aktivnih spojeva. U ovom preglednom radu prikazani su primjeri cikloadicijskih reakcija terminalnih alkina s azidima u području nukleozidne kemije s naglaskom na različite ciljeve provedenih modifikacija. Osim studija utjecaja 1,2,3-triazolnog prstena, kao novog strukturnog motiva, na biološka svojstva, brojni radovi govore o nizu drugih primjena tako modificiranih nukleozidnih derivata. Stoga je klik-kemija kao sintetski pristup moćan alat u postupku razvoja novih nukleozidnih derivata na relativno brz i jednostavan način.

\begin{tabular}{|c|c|}
\hline ODN & $\begin{array}{l}\text { - oligodeoksinukleotidi } \\
\text { - oligodeoxynucleotides }\end{array}$ \\
\hline PET & $\begin{array}{l}\text { - pozitronska emisijska tomografija } \\
\text { - Positron Emission Tomography }\end{array}$ \\
\hline POM & $\begin{array}{l}\text { - pivaloiloksimetil } \\
\text { - pivaloyloxymethyl }\end{array}$ \\
\hline RNA & $\begin{array}{l}\text { - ribonukleinska kiselina } \\
\text { - ribonucleic acid }\end{array}$ \\
\hline SAR & $\begin{array}{l}\text { - odnos struktura- aktivnost } \\
\text { - Structure-Activity Relationship }\end{array}$ \\
\hline SNP & $\begin{array}{l}\text { - polimorfizam pojedinačnog nukleotida } \\
\text { - Single Nucleotide Polymorphism }\end{array}$ \\
\hline THF & $\begin{array}{l}\text { - tetrahidrofuran } \\
\text { - tetrahydrofuran }\end{array}$ \\
\hline TMV & $\begin{array}{l}\text { - virus mozaične bolesti duhana } \\
\text { - Tobacco Mosaic Virus }\end{array}$ \\
\hline UV & $\begin{array}{l}\text { - ultraljubičasto } \\
\text { - Ultraviolet }\end{array}$ \\
\hline WHO & $\begin{array}{l}\text { - Svjetska zdravstvena organizacija } \\
\text { - World Health Organization }\end{array}$ \\
\hline$T_{\mathrm{m}}$ & $\begin{array}{l}\text { - temperatura mekšanja, }{ }^{\circ} \mathrm{C} \\
\text { - melting temperature, }{ }^{\circ} \mathrm{C}\end{array}$ \\
\hline
\end{tabular}

\section{Literatura \\ References}

1. E. De Clercq, H. J. Field, Antiviral prodrugs - The development of successful prodrug strategies for antiviral chemotherapy, Br. J. Pharmacol. 147 (2006) 1-11, doi: http://dx. doi.org/10.1038/sj.bjp.0706446.

2. R. F. Heck, Mechanism of arylation and carbomethoxylation of olefins with organopalladium compounds, J. Am. Chem. Soc. 91 (1969) 6707-6714, doi: http://dx.doi.org/10.1021/ ja01052a029.

3. L. A. Agrofoglio, I. Gillaizeau, Y. Saito, Palladium-assisted routes to nucleosides, Chem. Rev. 103 (2003) 1875-1916, doi: http://dx.doi.org/10.1021/cr010374q.

4. R. Kobetić, N. Biliškov, Heckova reakcija - moćno oruđe suvremene organske kemije, Kem. Ind. 56 (7-8) (2007) 391402.

5. J. L. Ruth, D. E. Bergstrom, C-5 substituted pyrimidine nucleosides. 1. Synthesis of C-5 allyl, propyl, and propenyl uracil and cytosine nucleosides via organopalladium intermediates, J. Org. Chem. 43 (1978) 2870-2876, doi: http:// dx.doi.org/10.1021/jo00408a026.

6. D. E. Bergstrom, J. L. Ruth, Synthesis of C-5 substituted pyrimidine nucleosides via organopalladium intermediates, J. Am. Chem. Soc. 98 (1976) 1587-1589, doi: http://dx.doi. org/10.1021/ja00422a056.

7. D. E. Bergstrom, J. L. Ruth, P. Warwick, C-5-Substituted pyrimidine nucleosides. 3. Reaction of allylic chlorides, alcohols, and acetates with pyrimidine nucleoside derived organopalladium intermediates, J. Org. Chem. 46 (1981) 1432-1441, doi: http://dx.doi.org/10.1021/jo00320a039.

8. P. Espinet, A. M. Echavarren, The Mechanisms of the Stille reaction, Angew. Chem. Int. Ed. 43 (2004) 4704-4734.

9. A. O. King, N. Okukado, E. Negishi, Highly general stereo-, regio-, and chemo-selective synthesis of terminal and internal conjugated enynes by the Pd-catalysed reaction of alkynylzinc reagents with alkenyl halides, J. Chem. Soc., Chem. Commun. 19 (1977) 683-684, doi: http://dx.doi. org/10.1039/c39770000683. 
10. Y. Hatanaka, T. Hiyama, Cross-coupling of organosilanes with organic halides mediated by a palladium catalyst and tris(diethylamino)sulfonium difluorotrimethylsilicate, J. Org. Chem. 53 (1988) 918-920, doi: http://dx.doi.org/10.1021/ jo00239a056.

11. H. C. Kolb, M. G. Finn, K. B. Sharpless, Click chemistry: diverse chemical function from a few good reactions, Angew. Chem. Int. Ed. 40 (2001) 2004-2021, doi: http://dx.doi. org/10.1002/1521-3773(20010601)40:11<2004::AIDANIE2004>3.3.CO;2-X.

12. J. F. Lutz, 1,3-Dipolar cycloadditions of azides and alkynes: A universal ligation tool in polymer and materials science, Angew. Chem. Int. Ed. 46 (2007) 1018-1025, doi: http:// dx.doi.org/10.1002/anie.200604050.

13. A. Michael, Ueber die Einwirkung von Diazobenzolimid auf Acetylendicarbonsäuremethylester, J. Prakt. Chem./Chem.Ztg. 48 (1893) 94-95, doi: http://dx.doi.org/10.1002/ prac. 18930480114.

14. R. Huisgen, 1,3-Dipolar cycloaddition chemistry, u A. Padwa (ur.), General heterocyclic chemistry Series Vol. 1, John Wiley \& Sons, New York, 1984, str. 1-176.

15. F. Himo, T. Lovell, R. Hilgraf, V. V. Rostovtsev, L. Noodleman, K. B. Sharpless, V. V. Fokin, Copper(I)-catalyzed synthesis of azoles. DFT study predicts unprecedented reactivity and intermediates, J. Am. Chem. Soc. 127 (2005) 210-216, doi: http://dx.doi.org/10.1021/ja0471525.

16. V. V. Rostovtsev, L. G. Green, V. V. Folkin, K. B. Sharpless, A stepwise Huisgen cycloaddition process: Copper(I)-catalyzed regioselective "ligation" of azides and terminal alkynes, Angew. Chem. Int. Ed. 41 (2002) 2596-2599, doi: http://dx. doi.org/10.1002/1521-3773(20020715)41:14<2596::AIDANIE2596>3.0.CO;2-4.

17. a) C. W. Tornøe, M. Meldal, Peptides 2001, u M. Lebl, R. A. Houghten (ur.), Proc. Am. Pept. Symp., Peptidotriazoles: Copper(I)-catalyzed 1,3-dipolar cycloadditions on solid-phase, American Peptide Society and Kluwer Academic Publishers, San Diego, 2001, str. 263-264.; b) C. W. Tornøe, C. Christensen, M. Meldal, Peptidotriazoles on solid phase: [1,2,3]-triazoles by regiospecific copper(I)-catalyzed 1,3-dipolar cycloadditions of terminal alkynes to azides, J. Org. Chem. 67 (2002) 3057-3064, doi: http://dx.doi. org/10.1021/jo011148j.

18. R. K. Smith, S. M. Reed, P. A. Lewis, J. D. Monnell, R. S. Clegg, K. F. Kelly, L. A. Bumm, J. E. Hutchison, P. S. Weiss, Phase separation within a binary self-assembled monolayer on Au\{111\} driven by an amide-containing alkanethiol, J. Phys. Chem. B 105 (2001) 1119-1122, doi: http://dx.doi. org/10.1021/jp0035129.

19. a) L. D. Pachón, J. H. Van Maarseveen, G. Rothenberg, Click chemistry: Copper clusters catalyse the cycloaddition of azides with terminal alkynes, Adv. Synth. Catal. 347 (2005) 811-815, doi: http://dx.doi.org/10.1002/adsc.200404383 b) Q. Wan, J. Chen, G. Chen, S. J. Danishefsky, A potentially valuable advance in the synthesis of carbohydrate-based anticancer vaccines through extended cycloaddition chemistry, J. Org. Chem. 71 (2006) 8244-8249, doi: http://dx.doi. org/10.1021/jo061406i.

20. F. Alonso, Y. Moglie, G. Radivoy, M. Yus, Copper nanoparticles in click chemistry: an alternative catalytic system for the cycloaddition of terminal alkynes and azides, Tetrahedron Lett. 50 (2009) 2358-2362, doi: http://dx.doi.org/10.1016/j. tetlet.2009.02.220.

21. a) M. Meldal, C. W. Tornøe, Cu-catalyzed azide-alkyne cycloaddition, Chem. Rev. 108 (2008) 2952-3015, doi: http:// dx.doi.org/10.1021/cr0783479; b) S. J. Hwang, S. H. Cho, $S$. Chang, Evaluation of catalytic activity of copper salts and their removal processes in the threecomponent coupling reactions, Pure Appl. Chem. 80 (2008) 873-879, doi: http:// dx.doi.org/10.1351/pac200880050873.

22. V. O. Rodionov, V. V. Fokin, M. G. Finn, Mechanism of the ligand-free Cu'-catalyzed azide-alkyne cycloaddition reaction, Angew. Chem. Int. Ed. 44 (2005) 2210-2215, doi: http://dx.doi.org/10.1002/anie.200461496
23. M. Ahlquist, V. V. Fokin, Enhanced reactivity of dinuclear copper(I) acetylides in dipolar cycloadditions, Organometallics 26 (2007) 4389-4391, doi: http://dx.doi.org/10.1021/ om700669v.

24. E. F. V. Scriven, K. Turnbull, Azides: their preparation and synthetic uses, Chem. Rev. 88 (1988) 297-368, doi: http:// dx.doi.org/10.1021/cr00084a001.

25. M. Ito, K. Koyakumaru, T. Ohta, H. Takaya, A simple and convenient synthesis of alkyl azides under mild conditions, Synthesis 4 (1995) 376-378, doi: http://dx.doi. org/10.1055/s-1995-3928.

26. T. Pathak, Azidonucleosides: Synthesis, reactions, and biological properties, Chem. Rev. 102 (2002) 1623-1668, doi: http://dx.doi.org/10.1021/cr0104532.

27. J. Andersen, U. Madsen, F. Björkling, X. Liang, Rapid synthesis of aryl azides from aryl halides under mild conditions, Synlett 14 (2005) 2209-2213.

28. K. Kacprzak, Efficient one-pot synthesis of 1,2,3-triazoles from benzyl and alkyl halides, Synlett 6 (2005) 943-946, doi: http://dx.doi.org/10.1055/s-2005-864809.

29. P. Appukkuttan, W. Dehaen, V. V. Fokin, E. Van der Eycken, A microwave-assisted click chemistry synthesis of 1,4-disubstituted 1,2,3-triazoles via a copper(I)-catalyzed three-component reaction, Org. Lett. 6 (2004) 4223-4225, doi: http:// dx.doi.org/10.1021/ol048341v.

30. A. K. Feldman, B. Colasson, V. V. Fokin, One-pot synthesis of 1,4-disubstituted 1,2,3-triazoles from in situ generated azides, Org. Lett. 6 (2004) 3897-3899, doi: http://dx.doi. org/10.1021/ol048859z.

31. J. Andersen, S. Bolvig, X. Liang, Efficient one-pot synthesis of 1-aryl 1,2,3-triazoles from aryl halides and terminal alkynes in the presence of sodium azide, Synlett 19 (2005) 29412947.

32. D. Kumar, V. Buchi Reddy, R. S. Varma, A facile and regioselective synthesis of 1,4-disubstituted 1,2,3-triazoles using click chemistry, Tetrahedron Lett. 50 (2009) 2065-2068, doi: http://dx.doi.org/10.1016/j.tetlet.2009.02.107.

33. J. S. Yadav, B. V. Subba Reddy, G. Madhusudham Reddy, D. Narasimha Chary, Three component, regioselective, one-pot synthesis of $\beta$-hydroxytriazoles from epoxides via "click reactions", Tetrahedron Lett. 9 (2007) 8773-8776, doi: http:// dx.doi.org/10.1016/j.tetlet.2007.09.160.

34. S. Chandrasekhar, D. Basu, C. Rambabu, Three-component coupling of alkynes, Baylis-Hillman adducts and sodium azide: a new synthesis of substituted triazoles, Tetrahedron Lett. 47 (2006) 3059-3063, doi: http://dx.doi.org/10.1016/j. tetlet.2006.03.037.

35. H. S. G. Beckmann, V. Wittmann, One-pot procedure for diazo transfer and azide-alkyne cycloaddition: Triazole linkages from amines, Org. Lett. 9 (2007) 1-4, doi: http:// dx.doi.org/10.1021/ol0621506.

36. a) K. Barral, A. D. Moorhouse, J. E. Moses, Efficient conversion of aromatic amines into azides: A one-pot synthesis of triazole linkages, Org. Lett. 9 (2007) 1809-1811, doi: http://dx.doi.org/10.1021/ol070527h; b) A. D. Moorhouse, J. E. Moses, Microwave enhancement of a "one-pot" tandem azidation-"click" cycloaddition of anilines, Synlett 14 (2008) 2089-2092, doi: http://dx.doi. org/10.1055/s-2008-1078019.

37. N. M. Smith, M. J. Greaves, R. Jewell, M. W. D. Perry, M. J. Stocks, J. P. Stonehouse, One-pot, three-component copper-catalysed "click" triazole synthesis utilising the inexpensive, shelf-stable diazotransfer reagent imidazole-1-sulfonyl azide hydrochloride, Synlett 9 (2009) 1391-1394, doi: http://dx.doi.org/10.1055/s-0029-1217175.

38. J. Y. Lau, R. C. Tam, T. J. Liang, Z. Hong, Mechanism of ac- 
tion of ribavirin in the combination treatment of chronic HCV infection, Hepatology 35 (2002) 1002-1009 i reference tamo citirane, doi: http://dx.doi.org/10.1053/ jhep.2002.32672.

39. Y. Mizushina, A. Matsukage, K. Sakaguchi, The biochemical inhibition mode of bredinin-5'-monophosphate on DNA polymerase beta, Biochim. Biophys. Acta 1403 (1998) 5-11 i reference tamo citirane, doi: http://dx.doi.org/10.1016/ S0167-4889(98)00027-5.

40. a) I. Perez-Castro, O. Caamano, F. Fernandez, M. D. Garcia, C. Lopez, E. De Clercq, Synthesis of 4-substituted-1,2,3-triazole carbanucleoside analogues of ribavirin via click chemistry, Org. Biomol. Chem. 5 (2007) 3805-3813, doi: http:// dx.doi.org/10.1039/b710348d; b) J. H. Cho, D. L. Bernard, R. W. Sidwell, E. R. Kern, C. K. Chu, Synthesis of cyclopentenyl carbocyclic nucleosides as potential antiviral agents against orthopoxviruses and SARS, J. Med. Chem. 49 (2006) 1140-1148, doi: http://dx.doi.org/10.1021/jm0509750; c) A. Goeminne, M. McNaughton, G. Bal, G. Surpateanu, P. Van der Veken, S. De Prol, W. Versees, J. Steyaert, S. Apers, A. Haemers, K. Augustyns, 1,2,3-Triazolylalkylribitol derivatives as nucleoside hydrolase inhibitors, Bioorg. Med. Chem. Lett. 17 (2007) 2523-2526, doi: http://dx.doi.org/10.1016/j. bmcl.2007.02.017; d) J. Broggi, S. Diez-Gonzalez, J. L. Petersen, S. Berteina-Raboin, S. P. Nolan, L. A. Agrofoglio, Study of copper(I) catalysts for the synthesis of carbanucleosides via azide-alkyne 1,3-dipolar cycloaddition, Synthesis 1 (2008) 141-148.

41. B. L. Wilkinson, H. Long, E. Sim, A. J. Fairbanks, Synthesis of arabino glycosyl triazoles as potential inhibitors of mycobacterial cell wall biosynthesis, Bioorg. Med. Chem. Lett. 18 (2008) 6265-6267, doi: http://dx.doi.org/10.1016/j. bmcl.2008.09.082.

42. B. K. Singh, A. K. Yadav, B. Kumar, A. Gaikwad, S. K. Sinha, V. Chaturvedi, R. P. Tripathi, Preparation and reactions of sugar azides with alkynes: synthesis of sugar triazoles as antitubercular agents, Carbohydr. Res. 343 (2008) 1153-1162, doi: http://dx.doi.org/10.1016/j.carres.2008.02.013.

43. R. A. Youcef, M. D. Santos, S. Roussel, J.-P. Baltaze, N. Lubin-Germain, J. Uziel, Huisgen cycloaddition reaction of C-alkynyl ribosides under micellar catalysis: Synthesis of ribavirin analogues, J. Org. Chem. 74 (2009) 4318-4323, doi: http://dx.doi.org/10.1021/jo900594x.

44. G. R. Lorello, M. Legault, B. Rakić, K. Bisgaard, J.-P. Pezacki, Synthesis and bioorthogonal coupling chemistry of a novel cyclopentenone-containing unnatural tyrosine analogue, Bioorg. Chem. 36 (2008) 105-111, doi: http://dx.doi. org/10.1016/j.bioorg.2007.12.006.

45. M. Nakahara, T. Kuboyama, A. Izawa, Y. Hari, T. Imanishi, S. Obika, Synthesis and base-pairing properties of C-nucleotides having 1-substituted 1H-1,2,3-triazoles, Bioorg. Med. Chem. Lett. 19 (2009) 3316-3319, doi: http://dx.doi. org/10.1016/j.bmcl.2009.04.063.

46. A. De La Hoz, A. Diaz-Ortiz, F. Langa, Microwaves in organic synthesis, u A. Loupy (ur.), Wiley-VCH Verlag $\mathrm{GmbH}$, Weinheim, 2002, str. 295-343.

47. a) C. O. Kappe, E. Van der Eycken, Click chemistry under non-classical reaction conditions, Chem. Soc. Rev. 39 (2010) 1280-1290, doi: http://dx.doi.org/10.1039/b901973c; b) D. Margetić, Microwave assisted cycloaddition reactions, Nova Science Publishers, Inc., New York, 2011.

48. a) K. Bougrin, A. Loupy, M. Soufiaoui, Microwave-assisted solvent-free heterocyclic synthesis, J. Photochem. Photobiol. C: Photochem. Rev. 6 (2005) 139-167, doi: http://dx.doi. org/10.1016/j.jphotochemrev.2005.07.001; b) R. Thorwirth, A. Stolle, B. Ondruschka, A. Wild, U. S. Schubert, Fast, ligand- and solvent-free copper-catalyzed click reactions in a ball mill, Chem. Commun. 47 (2011) 4370-4372, doi: http://dx.doi.org/10.1039/c0cc05657j.

49. R. Guezguez, K. Bougrin, K. El Akri, R. Benhida, A highly efficient microwave-assisted solvent-free synthesis of $\alpha$ - and $\beta$-2'-deoxy-1,2,3-triazolyl-nucleosides, Tetrahedron Lett. 47 (2006) 4807-4811, doi: http://dx.doi.org/10.1016/j.tetlet.2006.05.050.

50. L. Li, B. Lin, Z. Yang, L. Zhang, L. Zhang, A concise route for the preparation of nucleobase-simplified cADPR mimics by click chemistry, Tetrahedron Lett. 49 (2008) 4491-4493, doi: http://dx.doi.org/10.1016/j.tetlet.2008.05.076.

51. W. Li, Y. Xia, Z. Fan, F. Qu, Q. Wu, L. Peng, Bitriazolyl acyclonucleosides with antiviral activity against tobacco mosaic virus, Tetrahedron Lett. 49 (2008) 2804-2809, doi: http:// dx.doi.org/10.1016/j.tetlet.2008.02.139.

52. G. O'Mahony, E. Ehrman, M. Grøtli, Synthesis of adenosine-based fluorosides containing a novel heterocyclic ring system, Tetrahedron Lett. 46 (2005) 6745-6748, doi: http:// dx.doi.org/10.1016/j.tetlet.2005.07.115.

53. M. E. Ostergaard, D. C. Guenther, P. Kumar, B. Baral, L. Deobald, A. J. Paszczynski, P. K. Sharma, P. J. Hrdlicka, Pyrene-functionalized triazole-linked 2 -deoxyuridines-probes for discrimination of single nucleotide polymorphisms (SNPs), Chem. Commun. 46 (2010) 4929-4931, doi: http:// dx.doi.org/10.1039/c0cc01133a.

54. G. O'Mahony, E. Ehrman, M. Grøtli, Synthesis and photophysical properties of novel cyclonucleosides-substituent effects on fluorescence emission, Tetrahedron 64 (2008) 71517158, doi: http://dx.doi.org/10.1016/j.tet.2008.05.098.

55. C. Dyrager, K. Börjesson, P. Dinér, A. Elf, B. Albinsson, L. M. Wilhelmsson, M. Grøtli, Synthesis and photophysical characterisation of fluorescent 8-(1H-1,2,3-triazol-4-yl)adenosine derivatives, Eur. J. Org. Chem. 10 (2009) 1515-1521, doi: http://dx.doi.org/10.1002/ejoc.200900018.

56. URL: http://www.who.int/en/ (15.06.2014.)

57. M. C. Perry, The Chemotherapy Source Book, u J. W. Pine, Jr. (ur.), Lippincott Williams \& Wilkins, Philadelphia, 2012.

58. S. Meneni, I. Ott, C. D. Sergeant, A. Sniady, R. Gust, R. Dembinski, 5-Alkynyl-2'-deoxyuridines: chromatography-free synthesis and cytotoxicity evaluation against human breast cancer cells, Bioorg. Med. Chem. 15 (2007) 3082-3088, doi: http://dx.doi.org/10.1016/j.bmc.2007.01.048.

59. Y.-S- Lee, S. M. Park, H. M. Kim, S.-K. Park, K. Lee, C. W. Lee, B. H. Kim, C5-Modified nucleosides exhibiting anticancer activity, Bioorg. Med. Chem. Lett. 19 (2009) 4688-4691, doi: http://dx.doi.org/10.1016/j.bmcl.2009.06.072.

60. A. Montagu, V. Roy, J. Balzarini, R. Snoeck, G. Andrei, L. A. Agrofoglio, Synthesis of new C5-(1-substituted-1,2,3-triazol-4 or 5-yl)-2'-deoxyuridines and their antiviral evaluation, Eur. J. Med. Chem. 46 (2011) 778-786, doi: http:// dx.doi.org/10.1016/j.ejmech.2010.12.017.

61. S. M. Park, H. Yang, S.-K. Park, H. M. Kim, B. H. Kim, Design, synthesis, and anticancer activities of novel perfluoroalkyItriazole-appended 2'-deoxyuridines, Bioorg. Med. Chem. Lett. 20 (2010) 5831-5834, doi: http://dx.doi.org/10.1016/j. bmcl.2010.07.126.

62. a) A. J. Gutierrez, M. D. Matteucci, D. Grant, S. Matsumura, R. W. Wagner, B. C. Froehler, Antisense gene inhibition by C-5-substituted deoxyuridine-containing oligodeoxynucleotides, Biochemistry 36 (1997) 743-748, doi: http://dx.doi. org/10.1021/bi9620971; b) A. J. Gutierrez, T. J. Terhorst, M. D. Matteucci, B. C. Froehler, 5-Heteroaryl-2'-deoxyuridine analogs. Synthesis and incorporation into high-affinity oligonucleotides, J. Am. Chem. Soc. 116 (1994) 5540-5544, doi: http://dx.doi.org/10.1021/ja00092a003; c) P. Kočalka, N. K. Andersen, F. Jensen, P. Nielsen, Synthesis of 5-(1,2,3-tri- 
azol-4-yl)-2'-deoxyuridines by a click chemistry approach: Stacking of triazoles in the major groove gives increased nucleic acid duplex stability, ChemBioChem 8 (2007) 21062116, doi: http://dx.doi.org/10.1002/cbic.200700410; d) $R$. W. Sinkeldam, N. J. Greco, Y. Tor, Polarity of major grooves explored by using an isosteric emissive nucleoside, ChemBioChem 9 (2008) 706-709, doi: http://dx.doi.org/10.1002/ cbic. 200700714.

63. N. K. Andersen, N. Chandak, L. Brulíková, P. Kumar, M. D. Jensen, F. Jensen, P. K. Sharma, P. Nielsen, Efficient RNA-targeting by the introduction of aromatic stacking in the duplex major groove via 5-(1-phenyl-1,2,3-triazol-4-yl)-2'-deoxyuridines, Bioorg. Med. Chem. 18 (2010) 4702-4710, doi: http://dx.doi.org/10.1016/j.bmc.2010.05.019.

64. a) P. M. Chaudhary, S. R. Chavan, F. Shirazi, M. Razdan, P. Nimkar, S. P. Maybhate, A. P. Likhite, R. Gonnade, B. G. Hazara, M. V. Deshpande, S. R. Deshpande, Exploration of click reaction for the synthesis of modified nucleosides as chitin synthase inhibitors, Bioorg. Med. Chem. 17 (2009) 2433-2440, doi: http://dx.doi.org/10.1016/j. bmc.2009.02.019; b) K. K. Yeoh, T. D. Butters, B. L. Wilkinson, A. J. Fairbanks, Probing replacement of pyrophosphate via click chemistry; synthesis of UDP-sugar analogues as potential glycosyl transferase inhibitors, Carbohydr. Res. 344 (2009) 586-591, doi: http://dx.doi.org/10.1016/j.carres.2009.01.001; c) H. Ding, R. Yang, Y. Song, Q. Xiao, J. Wu, A highly efficient and selective synthesis of 1,2,3-triazole linked saccharide nucleosides via "click chemistry", Nucleos. Nucleot. Nucl. 27 (2008) 368-375, doi: http://dx.doi. org/10.1080/15257770801944055; d) Y. Byun, S. R. Vogel, A. J. Phipps, C. Carnrot, S. Eriksson, R. Tiwari, W. Tjarks, Synthesis and biological evaluation of inhibitors of thymidine kinase and thymidine monophosphate kinase from Bacillus anthracis, Nucleos. Nucleot. Nucl. 27 (2008) 244-260, doi: http://dx.doi.org/10.1080/15257770701845238.

65. G. O'Mahony, S. Svensson, A. Sundgreen, M. Grøtli, Synthesis of $2^{\prime}$-([1,2,3]triazol-1-yl)-2'-deoxyadenosine derivatives, Nucleos. Nucleot. Nucl. 27 (2008) 449-459, doi: http://dx. doi.org/10.1080/15257770802086880.

66. J. Cao, X. Huang, Solid-phase synthesis of heterocyclic nucleoside analogues: Substituted uracils tethered to isoxazoles, isoxazolines, and triazoles from a selenopolystyrene resin, J. Comb. Chem. 10 (2008) 526-533, doi: http://dx.doi. org/10.1021/cc800034v.

67. a) E. De Clercq, The acyclic nucleoside phosphonates from inception to clinical use: Historical perspective, Antiviral Res. 75 (2007) 1-13, doi: http://dx.doi.org/10.1016/j.antiviral.2006.10.006; b) E. De Clercq, A. Holy, Acyclic nucleoside phosphonates: a key class of antiviral drugs, Nat. Rev. Drug Disc. 4 (2005) 928-940, doi: http://dx.doi.org/10.1038/ nrd1877; c) A. Holy, Antiviral acyclic nucleoside phosphonates structure activity studies, Antiviral Res. 71 (2006) 248253, doi: http://dx.doi.org/10.1016/j.antiviral.2006.06.002; d) W. A. Lee, J. C. Martin, Perspectives on the development of acyclic nucleotide analogs as antiviral drugs, Antiviral Res. 71 (2006) 254-259, doi: http://dx.doi.org/10.1016/j.antiviral.2006.05.020.

68. H. Elayadi, M. Smietana, C. Pannecouque, P. Leyssen, J. Neyts, J.-J. Vasseur, H. B. Lazrek, Straightforward synthesis of triazoloacyclonucleotide phosphonates as potential HCV inhibitors, Bioorg. Med. Chem. Lett. 20 (2010) 7365-7368, doi: http://dx.doi.org/10.1016/j.bmcl.2010.10.046.

69. S. Trakossas, E. Coutouli-Argyropoulou, D. J. Hadjipavlou-Litina, Synthesis of modified triazole nucleosides possessing one or two base moieties via a click chemistry approach, Tetrahedron Lett. 52 (2011) 1673-1676, doi: http://dx.doi. org/10.1016/j.tetlet.2011.01.145.
70. X. Jin, R. Yang, P. Jin, Q. Xiao, Y. Ju, Synthesis 19 (2007) 29672972.

71. F. Seela, V. R. Sirivolu, Helv. Chim. Acta 90 (2007) 535-552, doi: http://dx.doi.org/10.1002/hlca.200790055.

72. R. Lucas, R. Zerrouki, R. Granet, P. Krausz, Y. Champavier, Tetrahedron 64 (2008) 5467-5471, doi: http://dx.doi. org/10.1016/j.tet.2008.04.006.

73. a) S. Röper, H. C. Kolb, Fragment-based approaches in drug discovery; methods and principles in medicinal chemistry, Vol. 34, u R. Mannhold, H. Kubinyi, G. Folkers (ur.), Click chemistry for drug discovery, Wiley- $\mathrm{VCH}$ Verlag $\mathrm{GmbH}$, Weinheim, 2006, str. 313-339; b) K. B. Sharpless, $R$. Manetsch, In situ click chemistry: a powerful means for lead discovery, Expert Opin. Drug Discovery 1 (2006) 525-538, doi: http://dx.doi.org/10.1517/17460441.1.6.525; c) G. C. Tron, T. Pirali, R. A. Billington, P. L. Canonico, G. Sorba, A. A. Genazzani, Click chemistry reactions in medicinal chemistry: applications of the 1,3-dipolar cycloaddition between azides and alkynes, Med. Res. Rev. 28 (2008) 278-308, doi: http:// dx.doi.org/10.1002/med.20107.

74. a) R. J. Pieters, D. T. S. Rijkers, R. M. J. Liskamp, Application of the 1,3-dipolar cycloaddition reaction in chemical biology: Approaches toward multivalent carbohydrates and peptides and peptide-based polymers, QSAR Comb. Sci. 26 (2007) 1181-1190, doi: http://dx.doi.org/10.1002/ qsar.200740075; b) A. J. Dirks, J. Cornelissen, F. L. van Delft, J. C. M. van Hest, R. J. M. Nolte, A. E. Rowan, F. Rutjes, From (bio)molecules to biohybrid materials with the click chemistry approach, QSAR Comb. Sci. 26 (2007) 12001210, doi: http://dx.doi.org/10.1002/qsar.200740085; c) C. M. Salisbury, B. F. Cravatt, Click chemistry-led advances in high content functional proteomics, QSAR Comb. Sci. 26 (2007) 1229-1238, doi: http://dx.doi.org/10.1002/ qsar.200740090; d) J. M. Baskin, C. R. Bertozzi, Bioorthogonal click chemistry: Covalent labeling in living systems, QSAR Comb. Sci. 26 (2007) 1211-1219, doi: http://dx. doi.org/10.1002/qsar.200740086; e) J. F. Lutz, Copper-free azide-alkyne cycloadditions: New insights and perspectives, Angew. Chem. Int. Ed. 47 (2008) 2182-2184, doi: http:// dx.doi.org/10.1002/anie.200705365; f) J. F. Lutz, H. G. Borner, Modern trends in polymer bioconjugates design, Prog. Polym. Sci. 33 (2008) 1-39, doi: http://dx.doi.org/10.1016/j. progpolymsci.2007.07.005; g) J.-F. Lutz, Z. Zarafshani, Efficient construction of therapeutics, bioconjugates, biomaterials and bioactive surfaces using azide-alkyne "click" chemistry, Adv. Drug Delive. Rev. 60 (2008) 958-970, doi: http:// dx.doi.org/10.1016/j.addr.2008.02.004.

75. a) W. H. Binder, C. Kluger, Azide/alkyne-"click" reactions: Applications in material science and organic synthesis, Curr. Org. Chem. 10 (2006) 1791-1815, doi: http://dx.doi. org/10.2174/138527206778249838; b) H. Nandivada, X. W. Jiang, J. Lahann, Click chemistry: Versatility and control in the hands of materials scientists, Adv. Mater. 19 (2007) 21972208, doi: http://dx.doi.org/10.1002/adma.200602739; c) D. Fournier, R. Hoogenboom, U. S. Schubert, Clicking polymers: a straightforward approach to novel macromolecular architectures, Chem. Soc. Rev. 36 (2007) 1369-1380, doi: http://dx.doi.org/10.1039/b700809k; d) P. L. Golas, K. Matyjaszewski, Click chemistry and ATRP: A beneficial union for the preparation of functional materials, QSAR Comb. Sci. 26 (2007) 1116-1134, doi: http://dx.doi.org/10.1002/ qsar.200740059.

76. a) O. S. Miljanic, W. R. Dichtel, I. Aprahamian, R. D. Rohde, H. D. Agnew, J. R. Heath, J. F. Stoddart, Rotaxanes and catenanes by click chemistry, QSAR Comb. Sci. 26 (2007) 11651174, doi: http://dx.doi.org/10.1002/qsar.200740070; b) D. D. Diaz, K. Rajagopal, E. Strable, J. Schneider, M. G. Finn, "Click" chemistry in a supramolecular environment: Stabi- 
lization of organogels by copper(I)-catalyzed azide-alkyne [3+2] cycloaddition, J. Am. Chem. Soc. 128 (2006) 60566057, doi: http://dx.doi.org/10.1021/ja061251w; c) D. W. Dodd, N. D. Jones, R. H. E. Hudson, Hydrogelation abilities of nucleobase-modified cytidines possessing substituted triazoles, Artif. DNA PNA XNA 1 (2010) 90-95, doi: http:// dx.doi.org/10.4161/adna.1.2.13975.

77. J. Gierlich, G. A. Burley, P. M. E. Gramlich, D. M. Hammond, T. Carell, Click chemistry as a reliable method for the high-density postsynthetic functionalization of alkyne-modified DNA, Org. Lett. 8 (2006) 3639-3642, doi: http://dx. doi.org/10.1021/ol0610946.

78. A. Nuzzi, A. Massi, A. Dondoni, Model studies toward the synthesis of thymidine oligonucleotides with triazole internucleosidic linkages via iterative $\mathrm{Cu}(\mathrm{I})$-promoted azide-alkyne ligation chemistry, QSAR Comb. Sci. 26 (2007) 1191-1199, doi: http://dx.doi.org/10.1002/qsar.200740079.

79. A. Dondoni, A. Marra, C-glycoside clustering on calix[4]arene, adamantane, and benzene scaffolds through 1,2,3-triazole linkers, J. Org. Chem. 71 (2006) 7546-7557 i reference tamo citirane, doi: http://dx.doi.org/10.1021/jo0607156.

80. a) J. A. F. Joosten, N. T. H. Tholen, F. Ait El Maate, A. J. Brouwer, G. W. van Esse, D. T. S. Rijkers, R. M. J. Liskamp, R. J. Pieters, High-yielding microwave-assisted synthesis of triazole-linked glycodendrimers by copper-catalyzed [3+2] cycloaddition, Eur. J. Org. Chem. 15 (2005) 3182-3185, doi: http://dx.doi. org/10.1002/ejoc.200500216; b) E. Fernandez-Megia, J. Correa, I. Rodríguez-Meizoso, R. Riguera, A click approach to unprotected glycodendrimers, Macromolecules 39 (2006) 2113-2120, doi: http://dx.doi.org/10.1021/ma052448w.

81. Z. Guo, A. Lei, X. Liang, Q. Xu, Click chemistry: a new facile and efficient strategy for preparation of functionalized HPLC packings, Chem. Commun. (2006) 4512-4514, doi: http:// dx.doi.org/10.1039/b610733h.

82. J. N. Wilson, E. T. Kool, Fluorescent DNA base replacements: reporters and sensors for biological systems, Org. Biomol. Chem. 4 (2006) 4265-4274, doi: http://dx.doi.org/10.1039/ b612284c.

83. a) H. Peacock, O. Maydanovych, P. A. Beal, $N^{2}$-Modified 2-aminopurine ribonucleosides as minor-groove-modulating adenosine replacements in duplex RNA, Org. Lett. 12 (2010) 1044-1047, doi: http://dx.doi.org/10.1021/ol100019r; b) A. Okamoto, Y. Saito, I. Saito, Design of base-discriminating fluorescent nucleosides, J. Photoch. Photobio. C 6 (2005) 108-122, doi: http://dx.doi.org/10.1016/j.jphotochemrev.2005.07.002.

84. P. Ding, D. Wunnicke, H.-J. Steinhoff, F. Seela, Site-directed spin-labeling of DNA by the azide-alkyne "click" reaction: Nanometer distance measurements on 7-deaza-2'-deoxyadenosine and 2 -deoxyuridine nitroxide conjugates spatially separated or linked to a "dA-dT" base pair, Chem. Eur. J. 16 (2010) 14385-14396, doi: http://dx.doi.org/10.1002/ chem. 201001572.
85. T. Kuboyama, M. Nakahara, M. Yoshino, Y. Cui, T. Sako, Y. Wada, T. Imanishi, S. Obika, Y. Watanabe, M. Suzuki, H. Doi, Stoichiometry-focused ${ }^{18}$ F-labeling of alkyne-substituted oligodeoxynucleotides using azido( $\left(\left[{ }^{18} \mathrm{~F}\right]\right.$ fluoromethyl) benzenes by Cu-catalyzed Huisgen reaction, Bioorg. Med. Chem. 19 (2011) 249-255, doi: http://dx.doi.org/10.1016/j. bmc.2010.11.033.

86. A. Dierckx, P. Diner, A. H. El-Sagheer, J. D. Kumar, T. Brown, M. Grøtli, L. M. Wilhelmsson, Characterization of photophysical and base-mimicking properties of a novel fluorescent adenine analogue in DNA, Nucleic Acids Res. 39 (2011) 4513-4524, doi: http://dx.doi.org/10.1093/nar/gkr010.

87. D. W. Dodd, K. N. Swanick, J. T. Price, A. L. Brazeau, M. J. Ferguson, N. D. Jones, R. H. E. Hudson, Blue fluorescent deoxycytidine analogues: convergent synthesis, solid-state and electronic structure, and solvatochromism, Org. Biomol. Chem. 8 (2010) 663-666, doi: http://dx.doi.org/10.1039/ b919921g.

88. C. Beyer, H.-A. Wagenknecht, In situ azide formation and "click" reaction of Nile Red with DNA as an alternative postsynthetic route, Chem. Commun. 46 (2010) 2230-2231, doi: http://dx.doi.org/10.1039/b924471a.

89. Y. Bourne, H. C. Kolb, Z. Radić, K. B. Sharpless, P. Taylor, P. Marchot, Freeze-frame inhibitor captures acetylcholinesterase in a unique conformation, Proc. Natl. Acad. Sci. USA 101 (2004) 1449-1454, doi: http://dx.doi.org/10.1073/ pnas.0308206100.

90. S. G. Agalave, S. R. Maujan, V. S. Pore, Click Chemistry: 1,2,3-Triazoles as pharmacophores, Chem. Asian J. 6 (2011) 2696-2718, doi: http://dx.doi.org/10.1002/ asia.201100432.

91. J. Rody, M. Slongo, Eur. Pat. 80-810394, 1981 (Chem. Abstr., 1981, 95, 187267).

92. a) A. M. S. Abdennabi, A. I. Abdulhadi, S. T. Abu-Orabi, H. Saricimen, The inhibition action of 1 (benzyl) 1-H-4,5-dibenzoyl-1, 2,3-triazole on mild steel in hydrochloric acid media, Corrosion Sci. 38 (1996) 1791-1800, doi: http://dx.doi. org/10.1016/S0010-938X(96)00087-X; b) K. K. Nippon Kasei Kogyo, Japan Jpn. Pat. 5610882, 1981 (Chem. Abstr., 1981, 96, 56298).

93. I. K. Boddy, G. G. Briggs, R. P. Harrison, T. H. Jones, M. J. O'Mahony, I. D. Marlow, B. G. Roberts, R. J. Willis, R. Bardsley, The synthesis and insecticidal activity of a series of 2-aryl-1,2,3-triazoles, J. Reid. Pestic. Sci. 48 (1996) 189-196, doi: http://dx.doi.org/10.1002/(SICI)10969063(199610)48:2<189::AID-PS461>3.3.CO;2-R.

94. K. H. Buechel, H. Gold, P. E. Frohberger, H. Kaspers, Ger. Pat. 2407305, 1975 (Chem. Abstr., 1975, 83, 206290).

95. a) F. Reisser, British. Pat. 8101239, 1981 (Chem. Abstr., 1981, 96, 69006).; b) H. R. Krueger, U. Schroeer, D. Baumert, H. Joppien, Ger. Pat. 2936951, 1981 (Chem. Abstr., 1981, 96, 52509). 


\section{SUMMARY \\ 1,3-Dipolar Cycloaddition (Part I): \\ Synthesis of 1,2,3-Triazole Derivatives in Nucleoside Chemistry \\ Dijana Saftić, ${ }^{*}$ Luka Krstulović, Miroslav Bajić, ${ }^{b}$ and Biserka Žinića}

Copper catalysed Huisgen 1,3-dipolar cycloaddition of azides and alkynes which leads to 1,4-disubstituted-1,2,3-triazoles is a frequently used method in synthetic organic chemistry. Due to the simple reaction conditions, it has occupied an important place in the field of nucleoside chemistry since it enables preparation of a large number of potentially biologically active compounds with a number of interesting additional properties induced by the presence of 1,2,3-triazole structural motif in the molecule.

\section{Keywords}

Click chemistry, nucleosides, 1,2,3-triazole nucleoside analogs

a Division of Organic Chemistry and

Review

Biochemistry, Ruđer Bošković Institute,

Received July 8, 2014

Bijenička cesta 54, 10000 Zagreb, Croatia

${ }^{\mathrm{b}}$ Department of Chemistry and Biochemistry,

Faculty of Veterinary Medicine, University

of Zagreb, Heinzelova 55, 10000 Zagreb,

Croatia 